\title{
Exogenous melatonin expediently modifies proteome of maize (Zea mays L.) embryo during seed germination
}

\author{
Izabela Kołodziejczyk $^{1} \cdot$ Katarzyna Dzitko $^{2} \cdot$ Rafał Szewczyk $^{3} \cdot$ Małgorzata M. Posmyk $^{1}$
}

Received: 26 November 2015/Revised: 6 May 2016/Accepted: 9 May 2016/Published online: 19 May 2016

(c) The Author(s) 2016. This article is published with open access at Springerlink.com

\begin{abstract}
Melatonin ( $N$-acetyl-5-methoxytryptamine) has a great potential for plant biostimulation. Its role in plant physiology is intensively explored, and its important function in plant stress defence frequently underlined. Melatonin is particularly effective when applied as an additional factor of seed priming. In the presented research, hydroconditioning was chosen experimentally as optimal for maize (Zea mays L.) seeds. The following seed variants were compared: controlled non-treated, hydroprimed with water and hydroprimed with melatonin solutions 50 and $500 \mu \mathrm{M}$. To identify modifications in proteome of maize seeds caused by the applied hydroconditioning techniques, protein extracts of germinated seed embryos $\left(24 \mathrm{~h}, 25^{\circ} \mathrm{C}\right)$ were separated by 2D-PAGE. Next, obtained maps of proteomes were compared (statistically and graphically) using PDQuest software, and characteristic spots of proteins were analysed qualitatively by mass-spectrometric techniques and identified in the Mascot protein databases. Research helped to identify hydropriming-associated proteins, and for the first time those which were expressed only in the presence of melatonin. Study confirmed that
\end{abstract}

Communicated by M Hajduch.

Małgorzata M. Posmyk

posmyk@biol.uni.lodz.pl

1 Department of Ecophysiology and Plant Development, Faculty of Biology and Environmental Protection, University of Lodz, 12/16 Banacha Str., 90-237 Lodz, Poland

2 Department of Immunology and Infectious Biology, Faculty of Biology and Environmental Protection, University of Lodz, 12/16 Banacha Str., 90-237 Lodz, Poland

3 Department of Industrial Microbiology and Biotechnology, Faculty of Biology and Environmental Protection, University of Lodz, 12/16 Banacha Str., 90-237 Lodz, Poland suitably selected pre-sowing treatment with melatonin, by embryo proteome modification, effectively prepares plants to adverse environmental conditions. In melatonin treated seeds during the initial state of embryos growth, even under optimal conditions, additional antioxidative, detoxifying, anti-stresses proteins were synthesized. Moreover, the supply of energy from seed storage substances was pretty intensified. The presented results partially explain how melatonin acts in plant stress defence, and why plants with higher melatonin content have exhibited increased capacity for stress tolerance.

Keywords Germination - Melatonin · Maize $\cdot$ Proteomics . Seed conditioning $\cdot$ Zea mays

\section{Introduction}

Problems related to seed quality, their germination, seedling emergence, and development under various environmental stresses firmly influence on crop establishment and prospective yield. Seed priming/conditioning has become a common practice to obtain optimal seed performance and ultimate yield notably under adverse germination conditions (Jisha et al. 2013; Mabhaudhi and Modi 2011). Conditioning is defined as pre-sowing treatment in water that, by controlled seed hydration, leads to limited imbibition but prevents the emergence of radicle (Bradford and Bewley 2002). Seeds after priming can be redried to the initial moisture content and stored. Such conditioning can accelerate seed germination, improve seedling uniformity, and increase yields in various crops (Eskandari 2013; Rahimi, 2013). Among various conditioning techniques, e.g., osmopriming, matrix priming and hydropriming - the latter one is simple and low cost and, therefore, extremely 
welcomed by farmers. Water pre-sowing treatments give the opportunity to apply biostimulators beneficial for plant. Biostimulators are different harmless substances mostly of natural origin that are able to improve plant development and stimulate life processes but in a different way than phytohormones and/or fertilizers. Their influence on plants is not the consequence of their direct ability to regulate metabolism, and their action could be multidirectional. The crucial point is that biostimulators in contrast to hormones improve plant metabolic processes without changing their natural pathway. They can facilitate the uptake of nutrients, stimulate root growth, also contribute to higher yield, and improve its quality via increase plants resistance/tolerance to unfavourable conditions, such as drought, extreme temperature, toxic pollutions, and so on (Basak 2008). Some studies indicate such a beneficial role of various substances, e.g. glycinebetaine, proline, natural nitrophenols (Asashi SL) as supplementation of irrigation into roots, with foliar fertilizers or protection spraying and also as seed treatment. Our previous research showed efficient conditioning methods for cucumber, cabbage and corn seed quality amelioration, with simultaneous melatonin application (Janas et al. 2009a; Posmyk et al. 2008, 2009a, b).

In general, results of our team suggest that melatonin ( $\mathrm{N}$-acetyl-5-methoxytryptamine) has a significant potential for biostimulation of plants (Janas and Posmyk 2013). Moreover, it is of natural origin, biodegradable, and harmless. Currently, the role of melatonin in plant physiology is being widely investigated. Solid evidence indicates melatonin as a growth promoter and plant development factor (Arnao and Hernández-Ruiz 2007; Chen et al. 2009; Hernández-Ruiz et al. 2005; HernándezRuiz and Arnao 2008; Sarrou et al. 2014; Zhang et al. 2014). The pre-sowing seed conditioning with melatonin protected cabbage seedlings against toxic effects of $\mathrm{Cu}^{2+}$ (Posmyk et al. 2008). Moreover, melatonin application into maize and cucumber seeds had a positive effect on seedling development and yield of plants that grown from them, especially those subjected to water-stress (Zhang et al. 2013) or cold (Posmyk et al. 2009a, b).

The physiological effects of seed conditioning have been extensively studied in a wide range of crops (Chen and Arora 2013; Di Girolamo and Barbanti 2012). However, until now, the performance of primed seeds can only be verified by germination tests, which provide retrospective indication of the conditioning affects (Gallardo et al. 2001). Therefore, it is necessary to develop molecular markers improved vigour of primed seeds for commercial seed lots. Proteomics become widely applicable in seed research as a novel tool for protein characterisation and function analysis (Catusse et al. 2011; Gallardo et al. 2001; $\mathrm{Wu}$ et al. 2011). Seeds develop differently in dicots and monocots, especially the changes induced by priming treatment. Therefore, the results obtained from Arabidopsis may not be applicable in monocot crops (e.g., maize). To date, the proteomic analysis of protein profiles of seed priming in maize (Zea mays L.) - one of the most important crops widely planted in the world-has not been done yet. There is lack of data concerning effects of melatonin applied by hydropriming on protein profiles in germinating seeds.

This study aimed to analyse the hydropriming-induced modifications in corn embryo proteome and to indicate hydropriming-associated and melatonin-associated proteins in corn seeds. Comparative proteomic analysis was applied to identify differentially expressed proteins in the untreated and hydroconditioned seeds and in those hydroprimed with melatonin. The possible roles of indicated proteins in maize seed vigour were discussed.

\section{Materials and methods}

\section{Plant material}

Grains of Zea mays L. var. Ambrozja were provided by TORSEED (Torun, Poland). Before experiments, seeds were stored at room temperature, in darkness, under dry conditions, in tightly closed boxes.

\section{Hydropriming}

Hydropriming was conducted by corn grains imbibing at $25{ }^{\circ} \mathrm{C}$ for $3 \mathrm{~h}$, using distilled water or melatonin water solutions $(50$ or $500 \mu \mathrm{M})$. During conditioning seed, moisture content was increased from an initial $8.8 \%$ $( \pm 0.2)$ to final $36.8 \%( \pm 2.3)$. The water quantity needed to enhance seed humidity was established experimentally. After soaking, seeds were redrying during 3 days at room temperature $\left(20-23{ }^{\circ} \mathrm{C} ; 40 \pm 5 \% \mathrm{RH}\right)$ to obtain initial water content. Maize seed variants: non-treated (nt-gel A), hydroprimed (H-gel B), hydroprimed with melatonin 50, and $500 \mu \mathrm{M}$ (HMel50 — gel C and HMel500—gel D, respectively).

\section{Seed germination}

All investigated seed variants were germinated in darkness at $25{ }^{\circ} \mathrm{C}$ for $24 \mathrm{~h}$. Afterwards, axes were isolated, treated with liquid nitrogen, and then lyophilized.

\section{Protein preparation}

Lyophilized tissue (200 mg) was homogenised (in ice bath) with $1.5 \mathrm{ml}$ of extraction buffer $50-\mathrm{mM}$ TrisHCl (pH 7.7) containing: $0.5-\mathrm{mM}$ deoxycholate sodium salt (DOXC); 
10-mM DL-dithiothreitol (DDT); and 10-mM EDTA; 1-mM phenylmethanesulfonylfluoride (PMSF). The homogenate was centrifuged: $20,000 \mathrm{~g} / 5^{\circ} \mathrm{C} / 10 \mathrm{~min}$. The pellet was discarded, whereas proteins resuspended in the collected supernatant were precipitated with $0.07 \%$ mercaptoethanol and $10 \%$ trichloroacetic acid (TCA) in acetone, at $0{ }^{\circ} \mathrm{C}$, during $45 \mathrm{~min}$. The mixture was centrifuged at $20,000 \mathrm{~g}$ for $10 \mathrm{~min}$ at $5^{\circ} \mathrm{C}$. The obtained pellet with precipitated proteins was then washed twice with $0.07 \%$ mercaptoethanol in acetone. After the final centrifugation: $3000 \mathrm{~g} / 5^{\circ} \mathrm{C} / 5 \mathrm{~min}$, sediment was vacuum-dried and then rediluted in buffer of Rabilloud consisting of: 65-mM DTT, $4 \%$ CHAPS and $8 \mathrm{M}$ urea. The proteins content was estimated in 96 microplates by Bradford (1976) method. The protein extracts were stored at $-20{ }^{\circ} \mathrm{C}$ and then used for 2D PAGE.

\section{2-D protein separation and image analysis}

Protein separation and analysis was performed according to Kolodziejczyk et al. 2016. Samples of 300-mg proteins were applied to 11-cm IPG strips ( $\mathrm{pH} \mathrm{3-10,} \mathrm{non-linear}$ gradient ReadyStrip) in a Protean IEF cell (Bio-Rad, Hercules, CA) and in-gel rehydrated for $12 \mathrm{~h}$. According to the isoelectric point, proteins were separated in the IEFSYS (Scie-Plas Ltd. GB). Isoelectric focusing (first dimension separation) was performed at $18{ }^{\circ} \mathrm{C}$ for $72 \mathrm{~h}$ at 0-3000 V gradually changing (first $24 \mathrm{~h}$ : 0-1500 V; second: 1500-3000; third $3000 \mathrm{~V}$ ). Before the second dimension PAGE, the gel strips were equilibrated twice with Eq solution (Eq: 50-mM Tris- $\mathrm{HCl}, \mathrm{pH} 8.5,6 \mathrm{M}$ urea, $30 \%$ glycerol, $10 \%$ SDS) containing $1 \%$ DTT for $15 \mathrm{~min}$ and next with Eq solution containing $2.5 \%$ iodoacetamide. Then strips were applied to SDS-PAGE (4\% stacking gel and $12 \%$ analytical gel) and fixed with $0.5 \%$ agarose in $0.5 \mathrm{M}$ Tris- $\mathrm{HCl}$ buffer ( $\mathrm{pH}$ 6.8) and $10 \%$ SDS. Appropriate protein markers (Thermo Scientific Page-Ruler Plus Prestained Protein Ladder No 26619) were loaded beside the strip. PAGE was performed in TV400YK Cooled TwinPlate Maxi-Gel Electrophoresis Unit (Scie-Plas Ltd. GB) with SDS electrophoresis buffer containing: 25-mM Tris base, 192-mM glycine, $0.1 \%$ SDS; for $2 \mathrm{~h}$ at $100 \mathrm{~V}$ and next for $2 \mathrm{~h}$ at $200 \mathrm{~V}$, at constant temperature $25^{\circ} \mathrm{C}$. At least four independent biological replicates were performed to ensure the reliability of the results.

Separated proteins were visualised in gels using Imperial $^{\mathrm{TM}}$ Protein Stain (Pierce). Then, stained gels were scanned at 300-dpi resolution using an Epson Perfection V700 Photo scanner. Obtained images were analysed with the PDQuest version 8.0.1 software (BioRad). Sample quantification was performed with four analytical gels originating from independent biological replicas. The volume of each spot was normalised to a relative volume, and mean values calculated from repeated data were compared. Qualitative and quantitative analysis sets were prepared. The cutoff for differentially expressed proteins was a fivefold change.

\section{Protein digestion}

Indicated protein spots were cut out from stained gels and subjected to in-gel tryptic (Promega, Madison, WI) digestion, as it was described previously by Kołodziejczyk et al. 2016.

Every gel piece containing the protein of interest was first decolorized in solution: $50-\mathrm{mM} \mathrm{NH}_{4} \mathrm{HCO}_{3} /$ acetonitrile $(\mathrm{ACN})(50: 50, \mathrm{v} / \mathrm{v})$ for $15 \mathrm{~min}$ at room temperature. The colourless gel pieces were washed with ACN to dehydrate the band pieces. For reducing and alkylation, gel pieces were then washed with $10-\mathrm{mM}$ DTT in $100-\mathrm{mM} \mathrm{NH}_{4} \mathrm{HCO}_{3}$ and incubate at $56{ }^{\circ} \mathrm{C}$ for $30 \mathrm{~min}$, then with $50-\mathrm{mM}$ iodoacetamide in $100-\mathrm{mM} \mathrm{NH}_{4} \mathrm{HCO}_{3}$ and incubate at room temperature for $30 \mathrm{~min}$ in dark. Then, the pieces were washed twice alternately with $100-\mathrm{mM} \mathrm{NH}_{4} \mathrm{HCO}_{3}$ and $\mathrm{ACN}$. Finally, the band pieces were dried at room temperature and rehydrated overnight at $37{ }^{\circ} \mathrm{C}$ in $25-\mathrm{mM}$ $\mathrm{NH}_{4} \mathrm{HCO}_{3}$ with trypsin (Promega). After this digestion, gel bands were extracted twice with $2 \%$ ACN/0.1\% trifluoroacetic acid (TFA) to collect the remaining peptides. The obtained supernatant was used for LC-MS/MS analysis.

\section{LC-MS/MS analysis}

LC-MS/MS analysis was performed on Eksigent Express HT Micro LC and AB Sciex QTRAP 3200 mass spectrometer with a microspray ESI ion source installed, as it was described by Kołodziejczyk et al. 2016.

Samples were ultrasonicated for $30 \mathrm{~s}$, shaken on vortex, and centrifuged for $5 \mathrm{~min}$. $10 \mu \mathrm{l}$ of the protein sample was applied by injection mode directly on Eksigent C8-CL-120 column $(3 \mu \mathrm{m} 120 \AA, 0.5 \times 100 \mathrm{~mm})$ at $40{ }^{\circ} \mathrm{C}$. The mobile phase was: water with $0.1 \%$ formic acid (A) and ACN with $0.1 \%$ formic acid (B). Gradient profile $(10 \mu \mathrm{l} /$ min constant flow conditions) started from $95 \%$ A for $1 \mathrm{~min}$, followed by $60 \% \mathrm{~A}$ after $40 \mathrm{~min}$ and $5 \%$ in $45 \mathrm{~min}$ and maintained until $50 \mathrm{~min}$ of the run. The column equilibration under the initial gradient conditions was applied from 50.1 to $53 \mathrm{~min}$ and as a prerun for $1 \mathrm{~min}$ before subsequent injection. MS/MS detection was performed using information-dependent acquisition method (IDA) composed of mixed positive ionization scan modes and IDA criteria for dynamic $\mathrm{m} / \mathrm{z}$, filtering. The process was constructed as follows: enhanced MS scan (EMS), enhanced resolution scan (ER), IDA criteria and enhanced product ion scan (EPI). Overall survey of EMS scan parameters comprehended the mass range 500-1400 Da 
with scan speed $4000 \mathrm{Da} / \mathrm{s}$ and $50-70 \mathrm{~V}$ declustering potential (DP) values. ER scan was active in $250 \mathrm{Da} / \mathrm{s}$ scan rate $(\mathrm{DP}=50-70 \mathrm{~V})$ and was used for peptide charge determination. EPI scan was active in the range $50-1600 \mathrm{~m} / \mathrm{z}$ (DP $=60 \mathrm{~V}$ and optimised rolling collision energy) and was applied for mass spectra collection and for the peptide sequence analysis. The ion source parameters were: CUR: 25.00; TEM: 400.00; GS1: 20.00; GS2: 40.00; ihe: ON; IS: 5000.00; CAD: high. The most important IDA criteria applied for selective $\mathrm{m} / \mathrm{z}$ filtering were as follows: dynamic background subtraction-on, choose 1-3 most intense peaks from range $500-1400 \mathrm{~m} / \mathrm{z}$ which charge state is 2-4 (include unknown) and exceeds 10,000 counts intensity, exclude former target ions for $30 \mathrm{~s}$ after 3 occurrences and use enhanced resolution scan to confirm charge state.

\section{Database searching}

The ProteinPilot v 4.0.8 software (AB Sciex, USA) and the MASCOT search engine v. 2.3 were applied for the database searching, as those were described previously by Kołodziejczyk et al. 2016.

The data were searched against the Zea mays (over 212,000 sequences) database extracted from NCBI (version 05.2013). Mascot MS/MS ion searches were conducted using trypsin as the digesting enzyme, up to two missed cleavages were tolerated, and the following modifications were applied: acetyl (N-term), carbamidomethyl (C), carbamyl (N-term), deamidated (NQ), formyl (N-term), Gln to pyro-Glu (N-term Q), Glu to pyro-Glu (N-term E) and oxidation (M). The searches were performed with a peptide mass tolerance of $0.7 \mathrm{Da}$ and fragment ion mass tolerance of $0.3 \mathrm{Da}$. The proteins established by MASCOT searches were further processed using a BLAST search against the NCBI non-redundant protein sequence database (circa 39 million sequences) applying the algorithm of domain enhanced lookup time accelerated BLAST (DELTABLAST) to confirm and/or define the probable protein function.

\section{Results and discussion}

Positive effects of conditioning were not visible in corn seed germination tests performed under optimal temperature conditions. Except that hydroprimed seeds germinated more uniformly (smaller \pm SEM), both the germination rate and the final germination percentage were comparable in good quality control seeds and their primed equivalents (Janas et al. 2009a). However, subsequent experiments showed that the seedlings grown from the seeds hydroconditioned with melatonin extremely well-tolerated stresses of suboptimal temperature $\left(10{ }^{\circ} \mathrm{C}\right)$, and heavy metal contamination $\left(2.5 \mathrm{mM} \mathrm{Cu}^{2+}\right)$ and also regenerated much better after relief of stress. It was manifested by better growth (greater weight of seedlings) and higher chlorophyll content and phenolic synthesis in the seedlings developed from the seeds hydroprimed with melatonin (Janas et al. 2009a). These experiments of our team provoked reflection that if the effects of conditioning are not visible in seed parameters investigated under the optimal conditions maybe the explanation why the seedlings grown from the seeds pretreated with melatonin tolerate stresses so well can be found at the molecular/proteomic level.

That is why proteomes of embryos isolated from particular seed variants (nt, H, HMel50 and, HMel500) germinated $24 \mathrm{~h}$ at optimal temperature $\left(25^{\circ} \mathrm{C}\right)$ were compared. The seed variants: $n t$ and $\mathrm{H}$, were the reference for the detection of melatonin-associated proteins, since it is well known that already the conditioning with water provokes modifications in seed proteome (Catusse et al. 2011; Wu et al. 2011; Gallardo et al. 2001).

The protein maps made in four replicates pointed out a significant level of reproducibility. Specialised software was able to indicate as corresponding $\sim 95 \%$ of the stained protein spots in the replicated gel images. PDQuest densitometric analysis of master gels was principle for qualitative (Table 1) and quantitative analyses of particular experimental seed variants (Tables 2, 3). 130 protein spots were indicated on gel A-representing proteome of axes isolated from nt seed variant, 143 on gel $\mathrm{B}$-axes proteome from $\mathrm{H}$ seeds, 180 on gel $\mathrm{C}$-axes proteome from HMel50 seeds, and 160 on gel D-axes proteome from HMel500 seeds (Figs. 1, 2). Our data suggested that hydroconditioning and especially hydroconditioning supplemented with melatonin induced new proteins biosynthesis in grain embryonic axes (Fig. 2). Previous comparative proteomic analysis by Gong et al. (2013) identified eight protein spots, which markedly differed in abundance between the primed and unprimed maize seeds, while the abundance of approximately $98 \%$ spots was almost the same. However, the mentioned study was performed with dry-no imbibed/germinated primed and unprimed seeds. Thus, during the short hydropriming process, metabolic activities (such as protein synthesis and degradation) were quite low. We performed our study after first $24 \mathrm{~h}$ of germination under optimal conditions, when the metabolic processes were very intensive. Moreover, we used the relatively sensitive and effective Imperial $^{\mathrm{TM}}$ Protein Stain (Pierce)-in comparison with Coomassie Brilliant Blue or Silver Stain-to visualise proteins in 2-DE gels; thereby, even the changes of lowabundance proteins might be detected. 
Table 1 Identification of the proteins unique to different seed variants: control, non-treated (A), hydroprimed (B), all primed (B, $\mathrm{C}, \mathrm{D})$, all hydroprimed with melatonin $(\mathrm{C}, \mathrm{D})$ and characteristic of the seeds treated with $50-\mu \mathrm{M}$ (C) or $500-\mu \mathrm{M}$ (D) melatonin, determined after $24 \mathrm{~h}$ of germination at optimal $25^{\circ} \mathrm{C}$

\begin{tabular}{|c|c|c|c|c|c|c|c|c|c|}
\hline Spot No & $\begin{array}{l}\text { Function } \\
\text { category }\end{array}$ & Protein family & Protein name & $\begin{array}{l}\text { Accession } \\
\text { No }\end{array}$ & $\begin{array}{l}\text { Mascot } \\
\text { score }\end{array}$ & $\begin{array}{l}\% \\
\text { Cover }\end{array}$ & $\begin{array}{l}\text { Peptide } \\
+/-\end{array}$ & $\begin{array}{l}\text { MW } \\
{[\mathrm{kDa}]}\end{array}$ & $\mathrm{p} I$ \\
\hline \multicolumn{10}{|c|}{ Protein unique to control, non-primed seeds (1)-A } \\
\hline \multicolumn{10}{|c|}{ Protein destination and storage } \\
\hline 0402 & 06.13 & Phytepsin & $\begin{array}{l}\text { Aspartic proteinase oryzasin-1 } \\
\text { precursor [Zea mays] }\end{array}$ & gil226506070 & 65 & 10 & $3 / 1$ & 54.90 & 5.41 \\
\hline \multicolumn{10}{|c|}{ Protein unique to hydroprimed seeds $(0)-B$} \\
\hline \multicolumn{10}{|c|}{ Proteins unique to all primed seeds (14)-B, C, D } \\
\hline \multicolumn{10}{|c|}{ Metabolism } \\
\hline 4503 & 01.01 & $\begin{array}{l}\text { Trp-synth-beta } \\
\text { II }\end{array}$ & $\begin{array}{l}\text { Cysteine synthase precursor } \\
{[\text { Zea mays }]}\end{array}$ & gil295421203 & 321 & 40 & $13 / 7$ & 34.19 & 5.91 \\
\hline 1601 & 01.03 & Ribokinase pfkB & Adenosine kinase [Zea mays] & gil4582787 & 332 & 29 & $13 / 6$ & 36.01 & 5.23 \\
\hline 5301 & 01.04 & Pyrophosphatase & $\begin{array}{l}\text { Inorganic pyrophosphatase } \\
\text { [Zea mays] }\end{array}$ & gil414586181 & 59 & 5 & $1 / 1$ & 24.35 & 5.46 \\
\hline \multicolumn{10}{|l|}{ Energy } \\
\hline 5602 & 02.0102 & Gp dh N & $\begin{array}{l}\text { Glyceraldehyde-3-phosphate } \\
\text { dehydrogenase } 1 \text {, cytosolic isoform } \\
\text { X1 [Zea mays] }\end{array}$ & gil6016075 & 122 & 16 & $3 / 2$ & 31.97 & 6.4 \\
\hline 7502 & 02.0102 & Gp dh N & $\begin{array}{l}\text { Cytosolic glyceroldehyde-3- } \\
\text { phosphate dehydrogenase }\end{array}$ & gil6166167 & 76 & 18 & $5 / 1$ & 36.43 & 7.01 \\
\hline & & & GAPC3 [Zea mays] & & & & & & \\
\hline 2301 & 02.07 & $\begin{array}{l}\text { SugarP } \\
\text { isomerase }\end{array}$ & $\begin{array}{l}\text { 6-phosphogluconolactonase isoform } 1 \\
\text { [Zea mays] }\end{array}$ & gil414591367 & 98 & 22 & $7 / 3$ & 34.76 & 7.71 \\
\hline \multicolumn{10}{|c|}{ Protein destination and storage } \\
\hline 1801 & 06.01 & PDIb & $\begin{array}{l}\text { Protein disulphide isomerase (PDI) } \\
\text { [Zea mays] }\end{array}$ & gil145666464 & 447 & 33 & $25 / 12$ & 56.7 & 5.01 \\
\hline 2802 & 06.01 & Chaperonin like & Chaperonin 60 [Zea mays $]$ & gil257734900 & 79 & 9 & $4 / 1$ & 61.2 & 5.68 \\
\hline 8103 & 06.20 & Cupin 2 & Cupin family protein [Zea mays] & gil226509468 & 68 & 11 & $4 / 1$ & 56.49 & 6.1 \\
\hline \multicolumn{10}{|c|}{ Disease/defence } \\
\hline 3502 & 11.05 & SDR & General stress protein 39 [Zea mays] & gil414590804 & 79 & 14 & $5 / 1$ & 38.6 & 9.06 \\
\hline 4502 & 11.05 & SDR & General stress protein 39 [Zea mays] & gil195659117 & 709 & 47 & $29 / 17$ & 32.92 & 5.78 \\
\hline 3901 & 11.05 & HSP70 actin & $\begin{array}{l}\text { Heat shock } 70 \mathrm{kDa} \text { protein [Zea } \\
\text { mays] }\end{array}$ & gil414589839 & 141 & 15 & $9 / 2$ & 72.50 & 5.62 \\
\hline 6902 & 11.05 & MDR & $\begin{array}{l}\text { Alcohol dehydrogenase } 1 \text { isoform X1 } \\
\text { [Zea mays] }\end{array}$ & gil7262819 & 89 & 5 & $2 / 2$ & 40.96 & 6.28 \\
\hline 6001 & 11.06 & Thioredoxin like & $\begin{array}{l}\text { Thioredoxin homolog } 2 \text { protein } \\
\text { [Zea mays] }\end{array}$ & gil66841004 & 61 & 8 & $1 / 1$ & 13.03 & 6.19 \\
\hline \multicolumn{10}{|c|}{ Proteins unique to seeds hydroprimed with melatonin (14)—C, D } \\
\hline \multicolumn{10}{|l|}{ Energy } \\
\hline 6502 & 02.0102 & Gp dh C & $\begin{array}{l}\text { Glyceraldehyde-3-phosphate } \\
\text { dehydrogenase, partial [Zea mays] }\end{array}$ & gil6016075 & 182 & 12 & $4 / 2$ & 24.93 & 8.44 \\
\hline \multicolumn{10}{|c|}{ Cell growth/division } \\
\hline 7804 & 03.22 & APP MetAP & $\begin{array}{l}\text { Proliferation-associated protein } 2 \mathrm{G} 4 \\
\text { [Zea mays }]\end{array}$ & gil413945091 & 117 & 10 & $6 / 4$ & 43.20 & 6.58 \\
\hline \multicolumn{10}{|c|}{ Transcryption } \\
\hline 2503 & 04.01 & $\begin{array}{l}\text { Ribosomal L10 } \\
\text { P0 }\end{array}$ & $\begin{array}{l}\text { 60S acidic ribosomal protein } \mathrm{P} 0 \\
\text { [Zea mays] }\end{array}$ & gil413941828 & 124 & 9 & $4 / 3$ & 34.47 & 5.2 \\
\hline \multicolumn{10}{|c|}{ Protein synthesis } \\
\hline 0301 & 05.04 & EF1B & $\begin{array}{l}\text { Elongation factor 1-delta } 1 \\
\text { [Zea mays }]\end{array}$ & 1414887578 & 199 & 22 & $6 / 4$ & 24.84 & 4.39 \\
\hline
\end{tabular}


Table 1 continued

\begin{tabular}{|c|c|c|c|c|c|c|c|c|c|}
\hline Spot No & $\begin{array}{l}\text { Function } \\
\text { category }\end{array}$ & Protein family & Protein name & $\begin{array}{l}\text { Accession } \\
\text { No }\end{array}$ & $\begin{array}{l}\text { Mascot } \\
\text { score }\end{array}$ & $\begin{array}{l}\% \\
\text { Cover }\end{array}$ & $\begin{array}{l}\text { Peptide } \\
+/-\end{array}$ & $\begin{array}{l}\text { MW } \\
{[\mathrm{kDa}]}\end{array}$ & $\mathrm{p} I$ \\
\hline \multicolumn{10}{|c|}{ Protein destination and storage } \\
\hline 2604 & 06.07 & Aha1 $\mathrm{N}$ & $\begin{array}{l}\text { Activator of } 90 \mathrm{kDa} \text { heat shock } \\
\text { protein ATPase [Zea mays] }\end{array}$ & gil414869818 & 89 & 6 & $2 / 2$ & 38.58 & 5.33 \\
\hline 2501 & 06.13 & Ntn hydrolases & $\begin{array}{l}\text { Proteasome subunit alpha type } 1 \\
\text { [Zea mays }]\end{array}$ & gil226531007 & 277 & 46 & $11 / 7$ & 30 & 5,19 \\
\hline 3202 & 06.20 & Cupin 2 & Cupin family protein [Zea mays] & gil4139567 & 67 & 4 & $2 / 1$ & 71 & 6.30 \\
\hline 4301 & 06.20 & Cupin 2 & Globulin-1 S allele-like [Zea mays] & gil413956703 & 255 & 10 & $6 / 5$ & 71.09 & 6.31 \\
\hline 7401 & 06.20 & Cupin 2 & $\begin{array}{l}\text { Globulin-1 S allele precursor } \\
\text { [Zea mays] }\end{array}$ & gil195658011 & 136 & 11 & $5 / 2$ & 49.93 & 6.16 \\
\hline \multicolumn{10}{|c|}{ Transporters } \\
\hline 2801 & 07.25 & ABC ATPase & $\begin{array}{l}\text { ATP synthase subunit beta family } \\
\text { protein [Zea mays] }\end{array}$ & gil414880947 & 828 & 50 & $33 / 22$ & 59.28 & 5.95 \\
\hline \multicolumn{10}{|c|}{ Disease/defence } \\
\hline 3105 & 11.05 & $\begin{array}{l}\alpha \text {-crystallin- } \\
\text { Hsps }\end{array}$ & $\begin{array}{l}\text { Heat shock } 22 \mathrm{kDa} \text { protein } \\
\quad[\text { Zea mays }]\end{array}$ & gil195621504 & 104 & 16 & $3 / 2$ & 23.85 & 6.47 \\
\hline 7102 & 11.05 & $\begin{array}{l}\text { a-crystallin- } \\
\text { Hsps }\end{array}$ & $\begin{array}{l}\text { Class II heat shock protein } \\
\text { [Zea mays] }\end{array}$ & gil413939226 & 208 & 39 & $9 / 6$ & 18.34 & 6.6 \\
\hline 0203 & 11.06 & PITH & $\begin{array}{l}\text { Thioredoxin family Trp26 isoform } 4 \\
\text { [Zea mays] }\end{array}$ & gil414881868 & 177 & 27 & $6 / 4$ & 22.60 & 4.95 \\
\hline \multicolumn{10}{|c|}{ Secondary metabolism } \\
\hline 8506 & 20.01 & DAHP synth1 & $\begin{array}{l}\text { 2-dehydro-3-deoxyphosphooctonate } \\
\text { aldolase [Zea mays] }\end{array}$ & gil414878308 & 64 & 8 & $1 / 1$ & 15.89 & 5.07 \\
\hline \multicolumn{10}{|c|}{ Proteins unique to seeds hydroprimed with $50 \mu \mathrm{M}$ melatonin $(23)-\mathrm{C}$} \\
\hline \multicolumn{10}{|c|}{ Energy } \\
\hline 1501 & 02.01 & Bac FRK & Fructokinase 1 [Zea mays] & gil75293604 & 152 & 28 & $6 / 3$ & 34.67 & 4.87 \\
\hline 4805 & 02.01 & alkPPc & $\begin{array}{l}\text { 2,3-bisphosphoglycerate-independent } \\
\text { phosphoglycerate mutase isoform } \\
\text { XI [Zea mays] }\end{array}$ & gil551288 & 118 & 10 & $6 / 3$ & 60.58 & 5.29 \\
\hline 3805 & 02.01 & $\begin{array}{l}\text { TIM phosphate } \\
\text { binding }\end{array}$ & $\begin{array}{l}\text { Triosephosphate isomerase, cytosolic } \\
{[\text { Zea mays }]}\end{array}$ & gil257353728 & 64 & 10 & $3 / 1$ & 60.50 & 5.34 \\
\hline 7701 & 02.01 & $\begin{array}{l}\text { TIM phosphate } \\
\text { binding }\end{array}$ & $\begin{array}{l}\text { Aldolase1 [Zea mays] Fructose- } \\
\text { bisphosphate aldolase cytoplasmic } \\
\text { isozyme [Zea mays] }\end{array}$ & gil414879138 & 419 & 35 & $15 / 10$ & 38.57 & 7.52 \\
\hline 7603 & 02.0102 & Gp dh N & $\begin{array}{l}\text { Glyceraldehyde-3-phosphate } \\
\text { dehydrogenase } 1 \text { isoform } 1 \\
\text { [Zea mays] }\end{array}$ & gil413921396 & 351 & 45 & $10 / 7$ & 31.92 & 6.45 \\
\hline 7702 & 02.0102 & Gp dh N & $\begin{array}{l}\text { Glyceraldehyde-3-phosphate } \\
\text { dehydrogenase } 1 \text { cytosolic isoform } \\
\text { X1 [Zea mays] }\end{array}$ & gil413921395 & 115 & 13 & $3 / 1$ & 36.47 & 6.46 \\
\hline 2602 & 02.10 & CoA-ligase & $\begin{array}{l}\text { Succinyl-CoA ligase beta-chain } \\
\text { [Zea mays }]\end{array}$ & gil226510248 & 311 & 29 & $15 / 8$ & 45.17 & 5.99 \\
\hline 5504 & 02.10 & SDR & Malate dehydrogenase [Zea mays] & gil550576396 & 119 & 9 & $3 / 2$ & 35.62 & 7.63 \\
\hline \multicolumn{10}{|c|}{ Cell growth/division } \\
\hline 2401 & 03.01 & SMP, LEA & $\begin{array}{l}\text { Late embryogeneis abundant protein } \\
\text { D-34 [Zea mays] }\end{array}$ & gil414872767 & 226 & 17 & $4 / 4$ & 27.16 & 5.41 \\
\hline 0701 & 03.19 & UBQ & $\begin{array}{l}\text { DNA repair protein RAD23 } \\
\text { [Zea mays] }\end{array}$ & gil525344153 & 62 & 2 & $1 / 1$ & 42.57 & 4.61 \\
\hline \multicolumn{10}{|c|}{ Protein synthesis } \\
\hline 0303 & 05.04 & EF1B & Elongation factor 1-beta [Zea mays] & gil414887997 & 141 & 26 & $6 / 2$ & 23.4 & 4.55 \\
\hline
\end{tabular}


Table 1 continued

\begin{tabular}{|c|c|c|c|c|c|c|c|c|c|}
\hline Spot No & $\begin{array}{l}\text { Function } \\
\text { category }\end{array}$ & Protein family & Protein name & $\begin{array}{l}\text { Accession } \\
\text { No }\end{array}$ & $\begin{array}{l}\text { Mascot } \\
\text { score }\end{array}$ & $\begin{array}{l}\% \\
\text { Cover }\end{array}$ & $\begin{array}{l}\text { Peptide } \\
+/-\end{array}$ & $\begin{array}{l}\text { MW } \\
{[\mathrm{kDa}]}\end{array}$ & $\mathrm{p} I$ \\
\hline \multicolumn{10}{|c|}{ Protein destination and storage } \\
\hline 0002 & 06.01 & $\begin{array}{l}\text { BBI plant serine } \\
\text { protease } \\
\text { inhibitors }\end{array}$ & $\begin{array}{l}\text { Hypothetical protein } \\
\text { ZEAMMB73_733594 [Zea mays] } \\
66 \% \text { identities to Bowman-Birk } \\
\text { trypsin inhibitor TI1 } \\
\text { [Coix lacryma-jobi] }\end{array}$ & gil414876537 & 54 & 4 & $1 / 1$ & 26.05 & 5.45 \\
\hline 6301 & 06.01 & SPFH like & Prohibitin2 [Zea mays] & gil7716458 & 79 & 13 & $2 / 2$ & 30.70 & 6.55 \\
\hline 8401 & 06.13 & Ntn hydrolases & $\begin{array}{l}\text { 20S proteasome alpha } 4 \text { subunit } \\
\text { [Zea mays] }\end{array}$ & gil414590073 & 201 & 18 & $6 / 4$ & 27.21 & 8.3 \\
\hline \multicolumn{10}{|c|}{ Cell structure } \\
\hline 2001 & 09.04 & ADF gelsolin & $\begin{array}{l}\text { Actin-depolymerizing factor } 3 \\
\text { [Zea mays] }\end{array}$ & gil413932602 & 258 & 65 & $10 / 6$ & 15.9 & 5.47 \\
\hline 8101 & 09.07 & $\mathrm{C} 2$ & $\begin{array}{l}\text { Unnamed protein product [Zea mays] } \\
98 \% \text { identities to ADP-ribosylation } \\
\text { factor GTPase-activating protein } \\
\text { AGD11 [Zea mays] }\end{array}$ & gil257692306 & 62 & 12 & $1 / 1$ & 18.92 & 6.59 \\
\hline \multicolumn{10}{|c|}{ Disease/defence } \\
\hline 0201 & 11.05 & $\begin{array}{l}\alpha \text {-crystallin- } \\
\text { Hsps }\end{array}$ & $\begin{array}{l}\text { Co-chaperone protein SBA1 } \\
\text { [Zea mays] }\end{array}$ & gil413920965 & 50 & 3 & $1 / 1$ & 20.80 & 4.43 \\
\hline 0202 & 11.05 & ТCTP & $\begin{array}{l}\text { Translationally controlled tumour } \\
\text { protein homolog [Zea mays] }\end{array}$ & gil413935193 & 69 & 16 & $4 / 1$ & 18.68 & 4.52 \\
\hline 0501 & 11.05 & USP & USP family protein [Zea mays] & gil413952234 & 81 & 6 & $1 / 1$ & 27.12 & 4.88 \\
\hline 2601 & 11.05 & GAT 1 & $\begin{array}{l}\text { Hypothetical protein } \\
\text { ZEAMMB73_682876 [Zea mays] } \\
88 \% \text { identities to Protein DJ-1 } \\
\text { homolog B-like [Setaria italic] }\end{array}$ & gil413954138 & 195 & 13 & $7 / 4$ & 42.22 & 5.51 \\
\hline 2402 & 11.06 & $\begin{array}{l}\text { Glo EDI BRP } \\
\text { like }\end{array}$ & Glyoxalase I [Zea mays] & gil37932483 & 120 & 23 & $7 / 3$ & 35.14 & 6.62 \\
\hline 6201 & 11.06 & Thioredoxin like & $\begin{array}{l}\text { 1-Cys peroxiredoxin antioxidant } \\
\text { PER1 [Zea mays] }\end{array}$ & gil414887819 & 165 & 28 & $6 / 3$ & 24.96 & 6.38 \\
\hline 6402 & 11.06 & Esterase lipase & Esterase D [Zea mays] & gil413951351 & 121 & 10 & $2 / 2$ & 31.87 & 6.13 \\
\hline \multicolumn{10}{|c|}{ Proteins unique to seeds hydroprimed with $500 \mu \mathrm{M}$ melatonin (3)-D } \\
\hline \multicolumn{10}{|c|}{ Metabolism } \\
\hline 0901 & $01 . \ldots$ & Transferases & Transferase [Zea mays] & gil126633162 & 62 & 4 & $2 / 1$ & 75.4 & 5.16 \\
\hline 5803 & 01.03 & $\begin{array}{l}\text { TIM phosphate } \\
\text { binding }\end{array}$ & $\begin{array}{l}\text { Inosine-5-monophosphate } \\
\text { dehydrogenase } 2 \text { [Zea mays] }\end{array}$ & gil226507304 & 81 & 11 & $4 / 2$ & 52.65 & 5.89 \\
\hline \multicolumn{10}{|c|}{ Protein synthesis } \\
\hline 5603 & 05.04 & ABC ATPase & $\begin{array}{l}\text { Translation elongation/initiation } \\
\text { factor family protein [Zea mays] }\end{array}$ & gil413932419 & 138 & 19 & $6 / 2$ & 43.84 & 5.76 \\
\hline
\end{tabular}

The table contains: spots excised from gels and numbered by PDQuest Software used for gel qualitative analysis; function category consistent with Nature (Bevan et al. 1998); protein family's, names and accession numbers consistent with NCBI database; Mascot score, sequence coverage $(\%)$, number of matched/unmatched $(+/-)$ peptides, MW $[\mathrm{kDa}]$ and $\mathrm{p} I$ values

\section{Influence of hydropriming on axes proteome in germinated maize grains}

Proteomic analysis of extracts from particular seed variants (nt, H, HMel50 and HMel500) enabled to identify 14 proteins, which appeared after seed conditioning (presented in gels $\mathrm{B}, \mathrm{C}$, and D-Table 1; Fig. 1BCD).
There were the proteins related to: (1) cysteine biosynthesis (cysteine synthase precursor-4503) - an endogenic sulphuric amino acid with -SH group and by glutathione metabolism connected/associated with the detoxification processes and regulation of cell redox status; (2) the preservation of intracellular adenylate pools due to regulation of extracellular adenosine levels (adenosine kinase- 
Table 2 Proteins showing different expressions in axes of the control nt seeds (A) germinated for $24 \mathrm{~h}$ at optimal $25^{\circ} \mathrm{C}$, to those from all hydroprimed seeds: H, HMel50, HMel500 (B, C, D)

\begin{tabular}{|c|c|c|c|c|c|c|c|c|c|c|c|}
\hline \multirow[t]{2}{*}{ Spot No } & \multirow{2}{*}{$\begin{array}{l}\text { Function } \\
\text { category }\end{array}$} & \multirow[t]{2}{*}{ Protein name } & \multirow{2}{*}{$\begin{array}{l}\text { Accession } \\
\text { No }\end{array}$} & \multirow{2}{*}{$\begin{array}{l}\text { Mascot } \\
\text { score }\end{array}$} & \multirow{2}{*}{$\begin{array}{l}\% \\
\text { Cover }\end{array}$} & \multirow{2}{*}{$\begin{array}{l}\text { Peptides } \\
+/-\end{array}$} & \multirow{2}{*}{$\begin{array}{l}\text { MW } \\
{[\mathrm{kDa}]}\end{array}$} & \multirow[t]{2}{*}{$\mathrm{p} I$} & \multicolumn{3}{|c|}{ Fold change $p \leq 0.01$} \\
\hline & & & & & & & & & $\mathrm{A} / \mathrm{B}$ & $\mathrm{A} / \mathrm{C}$ & $\mathrm{A} / \mathrm{D}$ \\
\hline \multicolumn{12}{|c|}{ Proteins up-regulated in $A$ in comparison with $B, C, D$} \\
\hline \multicolumn{12}{|c|}{ Metabolism } \\
\hline 1301 & 01.04 & Adenylate cyclase [Zea mays] & gil414888163 & 57 & 8 & $3 / 0$ & 23.51 & 5.18 & 4.99 & 1.14 & 5.45 \\
\hline \multicolumn{12}{|l|}{ Energy } \\
\hline 5601 & 02.10 & $\begin{array}{l}\text { Malate dehydrogenase, } \\
\text { cytoplasmic [Zea mays] }\end{array}$ & gil320449084 & 498 & 43 & $16 / 12$ & 35.50 & 5.76 & 3.04 & 19.3 & 2.65 \\
\hline \multicolumn{12}{|c|}{ Cell growth/division } \\
\hline 8803 & 03.01 & $\begin{array}{l}\text { Embryonic protein DC-8-like } \\
{[\text { Zea mays }]}\end{array}$ & gil413936531 & 107 & 5 & $2 / 2$ & 61.73 & 7.27 & 34.1 & 18.6 & \\
\hline \multicolumn{12}{|c|}{ Protein synthesis } \\
\hline 9701 & 05.04 & $\begin{array}{l}\text { Elongation factor } 1 \text { alpha } \\
\text { [Zea mays] }\end{array}$ & gil7230387 & 162 & 14 & $7 / 3$ & 49.12 & 9.2 & 1.8 & 7.6 & \\
\hline \multicolumn{12}{|c|}{ Protein destination and storage } \\
\hline 2903 & 06.01 & $\begin{array}{l}\text { Mitochondrial chaperonin-60 } \\
\text { [Zea mays] }\end{array}$ & gil22248 & 1342 & 47 & $49 / 33$ & 61.15 & 5.68 & 40.8 & 2.71 & 5.63 \\
\hline 4203 & 06.13 & $\begin{array}{l}\text { Proteasome subunit beta type } 6 \\
\text { precursor [Zea mays] }\end{array}$ & gil229612088 & 169 & 22 & $6 / 3$ & 26.16 & 5.47 & 7.63 & 1.13 & 2.23 \\
\hline 1702 & 06.13 & $\begin{array}{l}\text { Hypothetical protein } \\
\text { ZEAMMB73_715164 } \\
\text { [Zea mays] } \\
96 \% \text { identity to } 26 \mathrm{~S} \text { protease } \\
\text { regulatory subunit } 6 \mathrm{~A} \\
\text { homolog [Oryza sativa } \\
\text { Japonica Group] }\end{array}$ & gil413944465 & 77 & 13 & $6 / 2$ & 47.78 & 4.94 & 13.3 & 1.29 & 1.51 \\
\hline \multicolumn{12}{|c|}{ Cell structure } \\
\hline 2105 & 09.04 & $\begin{array}{l}\text { Actin depolymerizing factor } \\
\text { [Zea mays }]\end{array}$ & gil414873646 & 71 & 36 & $5 / 1$ & 15.89 & 5.46 & 1.11 & 4.19 & 5.97 \\
\hline \multicolumn{12}{|c|}{ Disease/defence } \\
\hline 5502 & 11.05 & $\begin{array}{l}\text { General stress protein } 39 \\
\text { [Zea mays }]\end{array}$ & gil414590803 & 829 & 50 & $24 / 18$ & 38.60 & 5.78 & 1.47 & 7.52 & 2.44 \\
\hline 2901 & 11.05 & $\begin{array}{l}\text { Unknown [Zea mays] } 98 \% \\
\text { identities to Heat shock } \\
70 \mathrm{kDa} \text { protein, } \\
\text { mitochondrial-like [Setaria } \\
\text { italica] }\end{array}$ & gil194688822 & 289 & 17 & $11 / 7$ & 72.62 & 5.54 & 8.62 & 6.37 & 3.77 \\
\hline 1001 & 11.06 & $\begin{array}{l}\text { Glyoxalase family protein } \\
\text { superfamily [Zea mays] }\end{array}$ & gil195604212 & 314 & 42 & $8 / 5$ & 15.07 & 5.47 & 76.6 & 1.98 & 1.98 \\
\hline \multicolumn{12}{|c|}{ Unclassified } \\
\hline 5402 & 13 & Secreted protein [Zea mays] & gil413951152 & 108 & 29 & $6 / 4$ & 27.33 & 5.84 & 12.6 & 17.4 & \\
\hline \multicolumn{12}{|c|}{ Proteins down-regulated in $\mathrm{A}$ in comparison with $\mathrm{B}, \mathrm{C}, \mathrm{D}$. } \\
\hline \multicolumn{12}{|c|}{ Energy } \\
\hline 4201 & 02.01 & $\begin{array}{l}\text { Triose-phosphate isomerase } \\
\text { [Zea mays] (EC 5.3.1.1) }\end{array}$ & gil414876338 & 187 & 25 & $5 / 5$ & 27.01 & 5.52 & & 0.11 & $\mathbf{0 . 1 0}$ \\
\hline 4701 & 02.01 & $\begin{array}{l}\text { Cytosolic 3-phosphoglycerate } \\
\text { kinase [Zea mays] }\end{array}$ & gil413935730 & 405 & 20 & $13 / 12$ & 60.80 & 9.41 & 6.85 & 0.15 & 0.22 \\
\hline 8601 & 02.0102 & $\begin{array}{l}\text { Fructose-bisphosphate aldolase } \\
\text { [Zea mays] }\end{array}$ & gil413951593 & 536 & 38 & $21 / 13$ & 38.44 & 6.96 & 0.03 & 0.17 & 0.09 \\
\hline 8604 & 02.0102 & $\begin{array}{l}\text { Fructose-bisphosphate aldolase, } \\
\text { cytoplasmic isozyme } \\
\text { [Zea mays] }\end{array}$ & gil113621 & 115 & 9 & $2 / 2$ & 38.58 & 7.52 & 0.01 & 0.39 & 0.02 \\
\hline
\end{tabular}


Table 2 continued

\begin{tabular}{|c|c|c|c|c|c|c|c|c|c|c|c|}
\hline \multirow[t]{2}{*}{ Spot No } & \multirow{2}{*}{$\begin{array}{l}\text { Function } \\
\text { category }\end{array}$} & \multirow[t]{2}{*}{ Protein name } & \multirow{2}{*}{$\begin{array}{l}\text { Accession } \\
\text { No }\end{array}$} & \multirow{2}{*}{$\begin{array}{l}\text { Mascot } \\
\text { score }\end{array}$} & \multirow{2}{*}{$\begin{array}{l}\% \\
\text { Cover }\end{array}$} & \multirow{2}{*}{$\begin{array}{l}\text { Peptides } \\
+/-\end{array}$} & \multirow{2}{*}{$\begin{array}{l}\text { MW } \\
{[\mathrm{kDa}]}\end{array}$} & \multirow[t]{2}{*}{$\mathrm{p} I$} & \multicolumn{3}{|c|}{ Fold change $p \leq 0.01$} \\
\hline & & & & & & & & & $\mathrm{A} / \mathrm{B}$ & $\mathrm{A} / \mathrm{C}$ & $\mathrm{A} / \mathrm{D}$ \\
\hline 8602 & 02.10 & $\begin{array}{l}\text { Succinyl-CoA ligase alpha- } \\
\text { chain } 2 \text { [Zea mays] }\end{array}$ & gil414887289 & 61 & 12 & $3 / 0$ & 34.19 & 8.16 & 0.31 & 0.02 & 0.08 \\
\hline \multicolumn{12}{|c|}{ Cell growth/division } \\
\hline 6602 & 03.01 & $\begin{array}{l}\text { Hypothetical protein } \\
\text { ZEAMMB73_579239 } \\
\text { [Zea mays] } 80 \% \text { identities to } \\
\text { LEA protein [Setaria italica] }\end{array}$ & gil413955864 & 66 & 11 & $3 / 1$ & 37.89 & 6.6 & 0.05 & 0.13 & 0.05 \\
\hline \multicolumn{12}{|c|}{ Transcryption } \\
\hline 8902 & 04.1922 & $\begin{array}{l}\text { Hypothetical protein } \\
\text { ZEAMMB73_983793 } \\
\text { [Zea mays] } 94 \% \text { identities to } \\
\text { Polyadenylate-binding protein } \\
\text { 2-like [Setaria italica] }\end{array}$ & gil414588971 & 62 & 7 & $4 / 0$ & 71.13 & 7.55 & 0.24 & 0.27 & 0.17 \\
\hline \multicolumn{12}{|c|}{ Protein destination and storage } \\
\hline 8202 & 06.01 & $\begin{array}{l}\text { 1-Cys peroxiredoxin antioxidant } \\
\text { [Zea mays] }\end{array}$ & gil87133468 & 115 & 10 & $4 / 2$ & 24.89 & 6.31 & & 0.07 & 0.10 \\
\hline 3101 & 06.02 & Globulin 2 [Zea mays] & gil414873301 & 291 & 14 & $8 / 6$ & 49.89 & 6.16 & 0.21 & $\mathbf{0 . 0 3}$ & 0.15 \\
\hline 6302 & 06.13 & $\begin{array}{l}\text { Proteasome subunit alpha type } \\
\text { [Zea mays] }\end{array}$ & gil414865138 & 504 & 49 & $17 / 13$ & 27.40 & 6.10 & 0.03 & 0.11 & 1.17 \\
\hline 5304 & 06.13 & $\begin{array}{l}\text { Proteasome subunit alpha type } \\
\text { [Zea mays] }\end{array}$ & gil414865138 & 330 & 39 & $13 / 9$ & 27.4 & 6.1 & 0.42 & 0.02 & \\
\hline 3702 & 06.20 & $\begin{array}{l}\text { Homogentisate 1,2-dioxygenase } \\
\text { [Zea mays] }\end{array}$ & gil413953601 & 149 & 7 & $7 / 3$ & 50.30 & 5.30 & 0.19 & 0.17 & 0.39 \\
\hline \multicolumn{12}{|c|}{ Signal transduction } \\
\hline 6003 & 10.0404 & $\begin{array}{l}\text { Nucleoside diphosphate kinase } \\
\text { [Zea mays] }\end{array}$ & gil414867768 & 84 & 10 & $1 / 1$ & 16.53 & 6.3 & 0.013 & 0.032 & 0.064 \\
\hline 8001 & 10.0404 & $\begin{array}{l}\text { Nucleoside diphosphate kinase } 4 \\
\text { [Zea mays] }\end{array}$ & gil413946787 & 64 & 4 & $1 / 0$ & 25.93 & 9.04 & 0.09 & 0.04 & 0.16 \\
\hline \multicolumn{12}{|c|}{ Disease/defence } \\
\hline 4601 & 11.02 & Protein Z [Zea mays] & gil195606550 & 141 & 16 & $10 / 5$ & 42.16 & 5.52 & 1.12 & 0.08 & 0.36 \\
\hline 5001 & 11.05 & $\begin{array}{l}16.9 \mathrm{kDa} \text { class I heat shock } \\
\text { protein } 1 \text { [Zea mays] }\end{array}$ & gil296512085 & 59 & 24 & $4 / 1$ & 17.05 & 6.77 & 0.10 & 0.66 & \\
\hline 7002 & 11.05 & $\begin{array}{l}\text { Stress-inducible membrane pore } \\
\text { protein [Zea mays] }\end{array}$ & gil195642018 & 146 & 40 & $5 / 3$ & 17.80 & 6.41 & & 0.39 & 0.02 \\
\hline 3301 & 11.05 & $\begin{array}{l}\text { General stress protein } 39 \\
\text { [Zea mays }]\end{array}$ & gil414590803 & 71 & 6 & $2 / 1$ & 38.6 & 9.06 & 0.11 & 0.04 & \\
\hline \multicolumn{12}{|c|}{ Unclassified } \\
\hline 8003 & 13 & $\begin{array}{l}\text { CBS domain protein isoform } 3 \\
\text { [Zea mays }]\end{array}$ & gil414872657 & 359 & 40 & $11 / 8$ & 22.48 & 9.35 & 0.37 & 0.11 & 0.11 \\
\hline
\end{tabular}

The table contains: spots excised from gels and numbered by PDQuest Software used for quantitative gel analysis; function category consistent with Nature (Bevan et al. 1998); protein names and accession numbers consistent with NCBI database; Mascot score, sequence coverage (\%), number of matched/unmatched $(+/-)$ peptides, $\mathrm{MW}[\mathrm{kDa}]$ and $\mathrm{p} I$ values; and relative abundance fold change in comparison with control nt (A) seeds $(p \leq 0.01)$-bolded number indicate $\geq 5$-fold changes in protein expression in the compared variants

1601); and (3) phosphate metabolism (inorganic pyrophosphatase-5301).

In the axes of primed seeds, there were also a number of additional enzymes involved in cell energy metabolism: glyceraldehyde-3-phosphate dehydrogenase 1 cytosolic isoform X1-5602; cytosolic glyceraldehyde-3-phosphate dehydrogenase GAPC3-7502; 6-phosphogluconolactonase isoform 1-2301 (Table 1; Fig. 1BCD). These enzymes are involved in gluconeogenesis and glycolysis, also in the pentose phosphate pathway (the latter one). Improvement of the energy acquisition from sugar turnover is of utmost importance for growth and development of 
Table 3 Proteins showing different expressions in axes of the hydroprimed seeds (B) germinated $24 \mathrm{~h}$ at optimal $25{ }^{\circ} \mathrm{C}$, to those from all seeds hydroprimed with melatonin: $\operatorname{HMel50,} \operatorname{HMel500}(\mathrm{C}, \mathrm{D})$

\begin{tabular}{|c|c|c|c|c|c|c|c|c|}
\hline \multirow[t]{2}{*}{ Spot No } & \multirow[t]{2}{*}{$\begin{array}{l}\text { Function } \\
\text { category }\end{array}$} & \multirow[t]{2}{*}{ Protein name } & \multirow[t]{2}{*}{$\begin{array}{l}\text { Accession } \\
\text { No }\end{array}$} & \multirow[t]{2}{*}{$\begin{array}{l}\text { Mascot } \\
\text { score }\end{array}$} & \multirow[t]{2}{*}{$\begin{array}{l}\% \\
\text { Cover }\end{array}$} & \multirow[t]{2}{*}{$\begin{array}{l}\text { Peptides } \\
+/-\end{array}$} & \multirow[t]{2}{*}{$\begin{array}{ll}\mathrm{MW} & \mathrm{p} I \\
{[\mathrm{kDa}]} & \end{array}$} & $\begin{array}{l}\text { Fold } \\
\text { change } \\
p \leq 0.01\end{array}$ \\
\hline & & & & & & & & $\mathrm{B} / \mathrm{C}$ \\
\hline
\end{tabular}

\section{Proteins up-regulated in $\mathrm{B}$ in comparison with $\mathrm{C}, \mathrm{D}$}

Energy

$8501 \quad 02.0102 \quad$ Cytosolic glyceraldehyde-3-phosphate dehydrogenase [Zea mays]

$860402.0102 \quad$ Fructose-bisphosphate aldolase, cytoplasmic isozyme [Zea mays]

Protein destination and storage

\begin{tabular}{|c|c|c|}
\hline 8103 & 06.20 & Cupin family protein [Zea mays] \\
\hline \multicolumn{3}{|c|}{ Cell structure } \\
\hline 2105 & 09.04 & Actin depolymerizing factor [Zea mays] \\
\hline \multicolumn{3}{|c|}{ Signal transduction } \\
\hline 6003 & 10.0404 & Nucleoside diphosphate kinase [Zea mays] \\
\hline 5503 & 10.0410 & $\begin{array}{l}\text { Guanine nucleotide-binding protein } \\
\beta \text {-subunit-like [Zea mays] }\end{array}$ \\
\hline \multicolumn{3}{|c|}{ Disease/defence } \\
\hline 1202 & 11.05 & Heat shock protein 26 [Zea mays] \\
\hline 5202 & 11.06 & 1-Cys peroxiredoxin antioxidant [Zea mays] \\
\hline 5502 & 11.05 & $\begin{array}{l}\text { General stress protein } 39 \text { SDR family protein } \\
\text { [Zea mays }]\end{array}$ \\
\hline 001 & 11.06 & Thioredoxin h2 protein [Zea mays] \\
\hline
\end{tabular}

$6001 \quad 11.06 \quad$ Thioredoxin h2 protein [Zea mays]

Proteins down-regulated in $\mathbf{B}$ in comparison with $\mathbf{C}, \mathrm{D}$

Metabolism

\begin{tabular}{|c|c|c|}
\hline 1601 & 01.03 & Adenosine kinase [Zea mays] \\
\hline 1602 & 01.01 & Agmatine deiminase [Zea mays] \\
\hline 3701 & 01.05 & $\begin{array}{l}\text { UTP-glucose-1-phosphate uridylyltransferase } \\
\text { [Zea mays] }\end{array}$ \\
\hline 4503 & 01.0102 & O-acetylserine (thiol) lyase [Zea mays] \\
\hline \multicolumn{3}{|c|}{ Energy } \\
\hline 2301 & 02.07 & $\begin{array}{l}\text { 6-phosphogluconolactonase isoform } 2 \\
\text { [Zea mays] }\end{array}$ \\
\hline 2701 & 02.0102 & Enolase [Zea mays] \\
\hline 4202 & 02.01 & $\begin{array}{l}\text { Triosephosphate isomerase, cytosolic } \\
\text { [Zea mays] }\end{array}$ \\
\hline 4602 & 02.10 & Malate dehydrogenase [Zea mays] \\
\hline 4701 & 02.01 & $\begin{array}{l}\text { Cytosolic 3-phosphoglycerate kinase } \\
\text { [Zea mays] }\end{array}$ \\
\hline 5602 & 02.0102 & $\begin{array}{l}\text { Glyceraldehyde-3-phosphate dehydrogenase } \\
2 \text {, cytosolic [Zea mays] }\end{array}$ \\
\hline 8601 & 02.0102 & Fructose-bisphosphate aldolase [Zea mays] \\
\hline 8602 & 02.10 & $\begin{array}{l}\text { Succinyl-CoA ligase alpha-chain } 2 \text { [Zea } \\
\text { mays }]\end{array}$ \\
\hline
\end{tabular}

\begin{tabular}{lrrlllll} 
gil4582787 & 332 & 29 & $13 / 6$ & 36.01 & 5.23 & $\mathbf{0 . 0 8}$ & $\mathbf{0 . 0 8}$ \\
gil226508546 & 133 & 12 & $4 / 3$ & 41.6 & 4.93 & $\mathbf{0 . 1 4}$ & $\mathbf{0 . 1 4}$ \\
gil212275097 & 281 & 21 & $10 / 6$ & 52.06 & 5.3 & $\mathbf{0 . 1 1}$ & 0.31 \\
gil758353 & 321 & 40 & $13 / 7$ & 34.19 & 5.91 & 0.61 & $\mathbf{0 . 1 8}$ \\
gil414591367 & 98 & 22 & $7 / 3$ & 34.76 & 7.71 & $\mathbf{0 . 1 4}$ & $\mathbf{0 . 0 7}$ \\
gil22273 & 690 & 34 & $15 / 11$ & 48.03 & 5.2 & $\mathbf{0 . 1 1}$ & \\
gil414876339 & 531 & 42 & $18 / 11$ & 33.04 & 6.96 & $\mathbf{0 . 1 9}$ & $\mathbf{0 . 1 5}$ \\
gil414871066 & 148 & 26 & $7 / 4$ & 35.59 & 5.4 & 0.40 & $\mathbf{0 . 1 6}$ \\
gil413935730 & 405 & 20 & $13 / 12$ & 60.80 & 9.41 & $\mathbf{0 . 0 2}$ & $\mathbf{0 . 0 3}$ \\
gil6016075 & 122 & 16 & $3 / 2$ & 31.97 & 6.4 & $\mathbf{0 . 1 7}$ & 0.56 \\
gil413951593 & 536 & 38 & $21 / 13$ & 38.44 & 6.96 & $\mathbf{0 . 0 3}$ & $\mathbf{0 . 1 7}$ \\
gil414887289 & 51 & 12 & $3 / 0$ & 34.19 & 8.16 & $\mathbf{0 . 0 7}$ & 0.24 \\
& & & & & & & \\
gil309557 & 79 & 9 & $4 / 1$ & 61.2 & 5.68 & 0.23 & $\mathbf{0 . 0 5}$ \\
gil22248 & 1342 & 47 & $49 / 33$ & 61.15 & 5.68 & $\mathbf{0 . 0 7}$ & $\mathbf{0 . 1 4}$ \\
gil414873301 & 291 & 14 & $8 / 6$ & 49.89 & 6.16 & $\mathbf{0 . 1 6}$ & 0.74 \\
gil195658 & 81 & 5 & $2 / 1$ & 49.93 & 6.16 & $\mathbf{0 . 0 3}$ & 0.23 \\
gil195658011 & 99 & 10 & $4 / 1$ & 49.89 & 6.16 & $\mathbf{0 . 0 6}$ & $\mathbf{0 . 1 4}$ \\
\hline
\end{tabular}

$\begin{array}{lccccccc}\text { gil6016075 } & 640 & 61 & 22 / 11 & 37.16 & 6.67 & 4.32 & \mathbf{6 . 6 2} \\ \text { gil113621 } & 115 & 9 & 2 / 2 & 38.58 & 7.52 & \mathbf{3 6 . 4} & 1.60 \\ & & & & & & & \\ \text { gil195606798 } & 68 & 11 & 4 / 1 & 56.49 & 6.1 & 4.16 & \mathbf{1 1 . 1} \\ & & & & & & & \\ \text { gil414873646 } & 71 & 36 & 5 / 1 & 15.89 & 5.46 & 3.76 & \mathbf{5 . 3 6} \\ & & & & & & & \\ \text { gil414867768 } & 84 & 10 & 1 / 1 & 16.53 & 6.3 & 2.57 & \mathbf{5 . 0 9} \\ \text { gil413948362 } & 176 & 12 & 5 / 4 & 36.21 & 6.13 & \mathbf{9 . 1 4} & 0.88 \\ & & & & & & & \\ \text { gil453670 } & 84 & 22 & 4 / 1 & 26.36 & 7.88 & 3.70 & \mathbf{6 0 . 8} \\ \text { gil|87133468 } & 204 & 29 & 7 / 4 & 24.96 & 6.38 & \mathbf{5 . 0 7} & 0.72 \\ \text { gil414590803 } & 829 & 50 & 24 / 18 & 38.60 & 5.78 & \mathbf{5 . 1 1} & 1.66 \\ \text { gil66841004 } & 61 & 8 & 1 / 1 & 13.03 & 6.19 & 2.31 & \mathbf{8 . 0 9}\end{array}$

Protein destination and storage

$2802 \quad 06.01 \quad$ Chaperonin 60 [Zea mays]

$2903 \quad 06.01 \quad$ Mitochondrial chaperonin-60 [Zea mays]

$3101 \quad 06.20 \quad$ Globulin 2 [Zea mays]

$3103 \quad 06.20 \quad$ Globulin-1 S allele precursor [Zea mays]

$4003 \quad 06.20 \quad$ Globulin-1 S allele precursor [Zea mays]

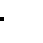


Table 3 continued

\begin{tabular}{|c|c|c|c|c|c|c|c|c|c|c|}
\hline \multirow[t]{2}{*}{ Spot No } & \multirow[t]{2}{*}{$\begin{array}{l}\text { Function } \\
\text { category }\end{array}$} & \multirow[t]{2}{*}{ Protein name } & \multirow[t]{2}{*}{$\begin{array}{l}\text { Accession } \\
\text { No }\end{array}$} & \multirow[t]{2}{*}{$\begin{array}{l}\text { Mascot } \\
\text { score }\end{array}$} & \multirow[t]{2}{*}{$\begin{array}{l}\% \\
\text { Cover }\end{array}$} & \multirow[t]{2}{*}{$\begin{array}{l}\text { Peptides } \\
+/-\end{array}$} & \multirow[t]{2}{*}{$\begin{array}{l}\mathrm{MW} \\
{[\mathrm{kDa}]}\end{array}$} & \multirow[t]{2}{*}{$\mathrm{p} I$} & \multicolumn{2}{|c|}{$\begin{array}{l}\text { Fold } \\
\text { change } \\
p \leq 0.01\end{array}$} \\
\hline & & & & & & & & & $\mathrm{B} / \mathrm{C}$ & $\mathrm{B} / \mathrm{D}$ \\
\hline 5304 & 06.13 & Proteasome subunit alpha type [Zea mays] & gil414865138 & 330 & 39 & $13 / 9$ & 27.4 & 6.1 & 0.04 & \\
\hline 4203 & 06.13 & $\begin{array}{l}\text { Unnamed protein product [Zea mays] } 97 \% \\
\text { identities to Proteasome subunit beta type } 6 \\
\text { precursor [Zea mays] }\end{array}$ & gil229612088 & 169 & 22 & $6 / 3$ & 26.16 & 5.47 & 0.15 & 0.29 \\
\hline \multicolumn{11}{|c|}{ Transporters } \\
\hline 1702 & 07.25 & $\begin{array}{l}\text { Hypothetical protein ZEAMMB73_715164 } \\
\text { [Zea mays] } 96 \% \text { identities to } 26 \mathrm{~S} \text { protease } \\
\text { regulatory subunit } 6 \mathrm{~A} \text { homolog } \\
\text { [Oryza sativa Japonica Group] }\end{array}$ & gil413944465 & 77 & 13 & $6 / 2$ & 47.78 & 4.94 & 0.10 & 0.11 \\
\hline \multicolumn{11}{|c|}{ Disease/defence } \\
\hline 1001 & 11.06 & $\begin{array}{l}\text { Glyoxalase family protein superfamily } \\
\text { [Zea mays] }\end{array}$ & gil195604212 & 314 & 42 & $8 / 5$ & 15.07 & 5.47 & $\mathbf{0 . 0 3}$ & $\mathbf{0 . 0 3}$ \\
\hline 3401 & 11.06 & $\begin{array}{l}\text { Glyoxalase family protein isoform } 2 \\
\text { [Zea mays] }\end{array}$ & gil413917004 & 579 & 55 & 19,13 & 32.32 & 5.82 & 0.08 & \\
\hline 4502 & 11.05 & $\begin{array}{l}\text { General stress protein } 39 \text { SDR family } \\
\text { protein [Zea mays] }\end{array}$ & gil195659117 & 709 & 47 & $29 / 17$ & 32.92 & 5.78 & 0.15 & 0.35 \\
\hline 4601 & 11.02 & Protein Z [Zea mays] & gil195606550 & 141 & 16 & $10 / 5$ & 42.16 & 5.52 & 0.07 & 0.33 \\
\hline 5102 & 11.05 & $\begin{array}{l}22.0 \mathrm{kDa} \text { class IV heat shock protein } \\
\text { precursor [Zea mays] }\end{array}$ & gil195644560 & 77 & 37 & $7 / 1$ & 22.88 & 6.01 & 0.10 & 0.11 \\
\hline 5201 & 11.06 & Glutathione transferase III(a) [Zea mays] & gil4468792 & 107 & 27 & $4 / 2$ & 23.79 & 9.33 & 0.04 & 0.20 \\
\hline 6702 & 11.05 & Formate dehydrogenase 1 [Zea mays] & gil413953926 & 95 & 14 & $4 / 2$ & 41.39 & 6.32 & 0.04 & 0.01 \\
\hline 7501 & 11.05 & $\begin{array}{l}\text { Hypothetical protein ZEAMMB73_578099 } \\
\text { [Zea mays] } 78 \% \text { identities to Stress } \\
\text { responsive protein [Zea mays] }\end{array}$ & gil414866592 & 268 & 22 & $15 / 10$ & 38.37 & 6.3 & 0.13 & 0.15 \\
\hline \multicolumn{11}{|c|}{ Secondary metabolism } \\
\hline 1303 & 20.1 & $\begin{array}{l}\text { Caffeoyl-CoA O-methyltransferase } 1 \\
\text { [Zea mays }]\end{array}$ & gil413925228 & 109 & 19 & $3 / 0$ & 27.3 & 5.09 & 0.13 & \\
\hline \multicolumn{11}{|c|}{ Unclassified } \\
\hline 4403 & 13 & Secreted protein [Zea mays] & gil413951152 & 238 & 44 & $12 / 7$ & 27.33 & 5.84 & 0.06 & 0.06 \\
\hline
\end{tabular}

The table contains: spots excised from gels and numbered by PDQuest Software used for quantitative gel analysis; function category consistent with Nature (Bevan et al. 1998); protein names and accession numbers consistent with NCBI database; Mascot score, sequence coverage (\%), number of matched/unmatched $(+/-)$ peptides, MW $[\mathrm{kDa}]$ and $\mathrm{p} I$ values; and relative abundance fold change in comparison with hydroprimed (B) seeds $(p \leq 0.01)$ —bolded number indicate $\geq 5$-fold changes in protein expression in the compared variants

seedlings, especially if starch is seed storage material, as is in the case of maize.

The appearance of new isomerases (1801), cupins (8103) and chaperonins (2802) involved in efficient protein destination and storage was also observed (Table 1; Fig. 1BCD). Cupins belong to superfamily of functionally diverse proteins, including seed storage proteins, auxin binding proteins, enzymes, transcription factors, and stressrelated proteins, which are involved in seed germination and seedlings development (Dunwell et al. 2004; Gong et al. 2013). Fu et al. (2011) suggested that cupin proteins, such as native germin and germin-like proteins, protected plant cells from the oxidative stress during seed germination.
Similar to the observations by other authors (Gallardo et al. 2001; Gong et al. 2013) in the conditioned plant material, a significant synthesis of so-called stress proteins (5 new spots) was indicated. They belonged to short-chain dehydrogenases/reductases family (SDR; general stress proteins 39-3502, 4502), heat shock proteins (HSP $70 \mathrm{kDa}-3901$ ), thioredoxins (TRX; thioredoxin homolog 2-6001) and anaerobic proteins (ANPs; alcohol dehydrogenase 1 isoform XI-6902) (Table 1, Fig. 1BCD).

HSPs were first described as associated with heat shock, but now, it is known that they are also overexpressed during other stresses, i.a. exposure to cold, UV light, and during wound healing or tissue remodelling. They may participate in intracellular distribution and degradation of 

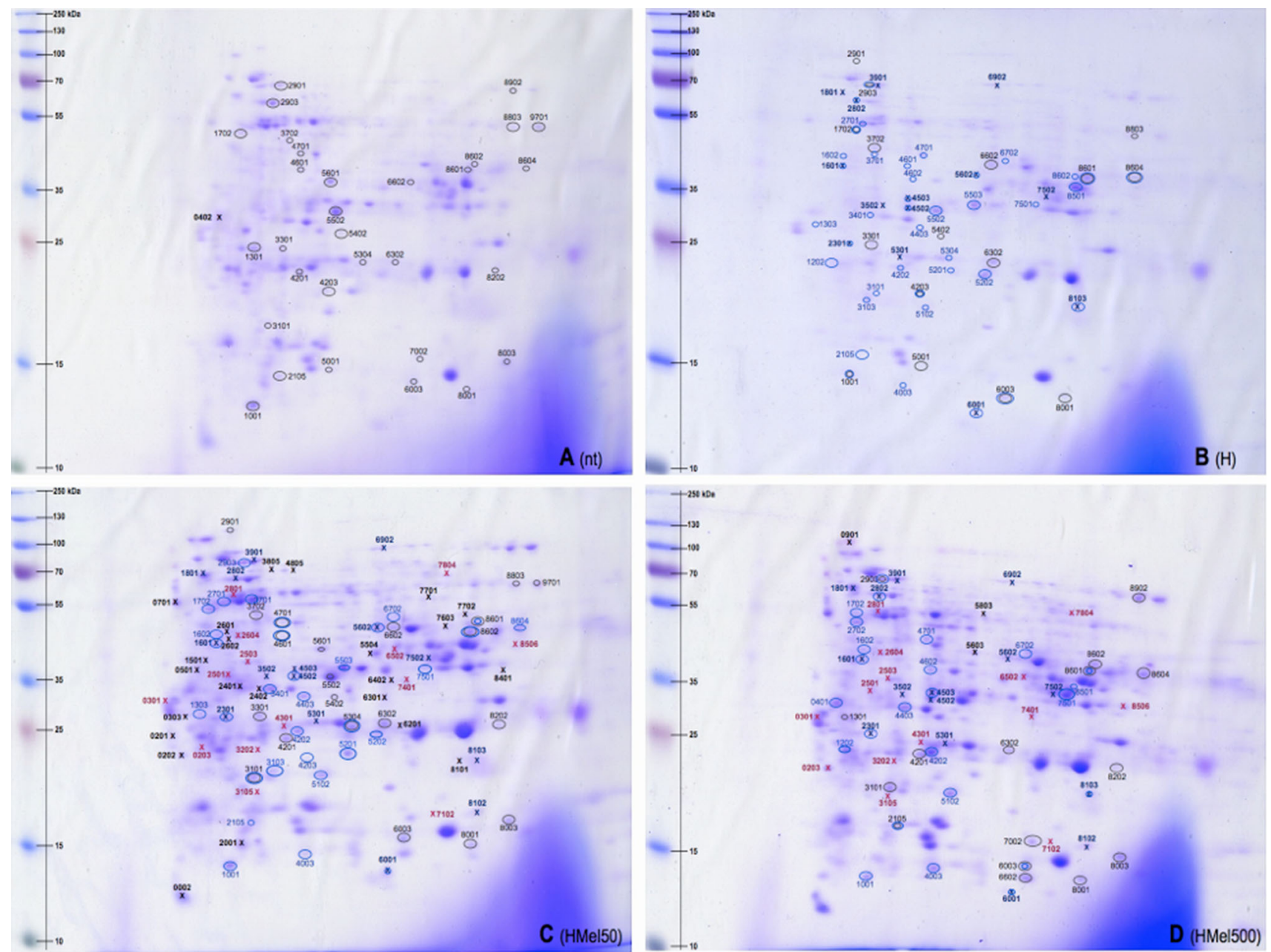

Fig. 1 Analytical gels of IEF/SDS-PAGE (2D) separation of proteins from: control nt (A), hydroprimed (B), hydroprimed with melatonin $50 \mu \mathrm{M}(\mathbf{C})$ and $500 \mu \mathrm{M}(\mathbf{D})$ seeds germinated in darkness at $25{ }^{\circ} \mathrm{C}$ for $24 \mathrm{~h}$. The proteins were separated by first dimensional pH 3-10 non-linear IPG strips and $12 \%$ vertical slab gels in the second dimension (ImperialTM Protein Stain). The proteins were numbered (PDQuest Software, BioRad) in a preparative 2D electrophoresis gel and excised for MS/MS analysis, corresponding to the spot/proteins in Tables 1,2 and 3. According to the qualitative

proteins, thus perform chaperone activity (Timperio et al. 2008), but also act as molecular factors in signal transduction cascades, affording a protective function during seed germination (Wang et al. 2004).

TRX is a small conservative protein, which causes the changes in redox state of target proteins by reversible oxidation of di-thiol - an active site exposed at the protein's surface (at least 30 target proteins functioning are regulated this way). Some of TRXs are transcription factors and enzymes involved in plant oxidative stress response. They can also limit stress via direct hydrogen peroxide and certain radicals scavenging, and/or by acting as a reductant for peroxiredoxins (Vieira Dos Santos and Rey 2006).

analysis, the black $X$ symbols mean proteins characteristic only of particular gels (A or $\mathrm{B}$ or $\mathrm{C}$ or $\mathrm{D}$ ), blue $X$ symbols mean proteins characteristic of all hydroprimed seeds (BCD), and red $X$ symbols means proteins characteristic of the seeds hydroprimed with melatonin (CD) (see Table 1). According to the quantitative analysis, ellipses are used to mark proteins five times upregulated or downregulated: black for A to B, C, D (see Table 2), blue for B to C, D (see Table 3)

ANPs mostly represent enzymes of the glycolytic and alcohol fermentation pathways. Their upregulation occurs in response to hypoxia/anoxia stress, but cross talk with other kinds of stresses is possible too (Grover et al. 2001).

Interestingly, under the influence of seed hydroconditioning aspartic proteinase oryzasin-1 precursor (0402) disappeared from embryo. It was characteristic only of the axes from control nt seeds (Table 1; Fig. 1A). This plant phytepsin is a homolog of lysosomal pepsins of mammals, and it appears in seeds but also in leaves, stems, flowers and roots. Phytepsin could be overexpressed in plant tissues undergoing apoptosis. It may influence metabolic turnover and other protein processing events. 


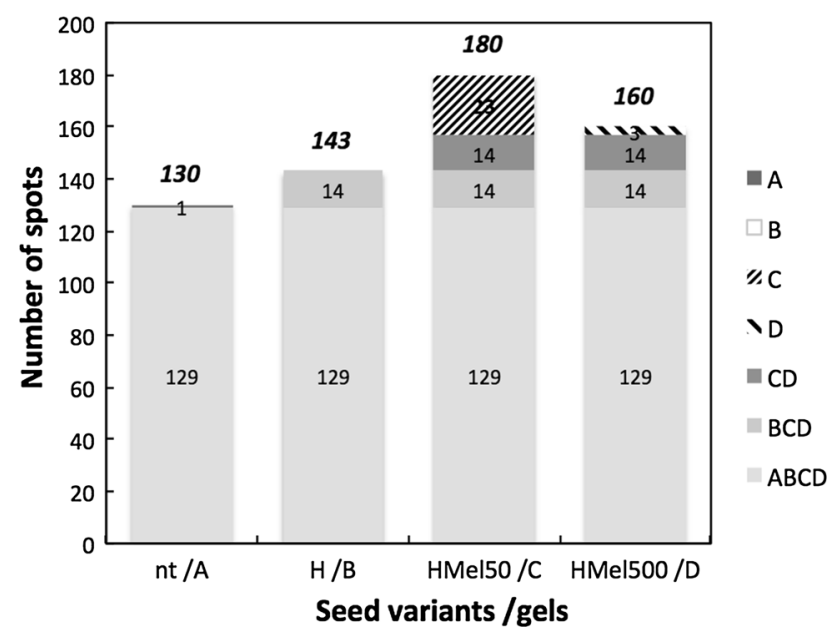

Fig. 2 Number of protein spots in particular gels: $A, B, C, D$, corresponding with seed variants: nt, H, HMel50, HMel500, respectively. The numbers of protein spots which occurred in certain types of gels were highlighted in different pattern: (1) common for all seeds $(A B C D),(2)$ common for the hydroprimed seeds $(B C D)$, (3) common for the melatonin treated seeds $(C D)$ and (4) unique for the particular seed variants ( $A$ or $B$ or $C$ or $D$ ). Bolded italics numbers above the bars indicate the total number of protein spots in the particular gels

There were no more proteins characteristic only of the control seed axes (gel A); nevertheless, several enzymes of primary metabolism showed here overexpression comparing with the axes of conditioned seeds (gels B, C, D), i.e. adenylate cyclase-1301 and cytoplasmic maleate dehydrogenase (MDH) -5601 (Table 2; Fig. 1A). Adenylate cyclase (AC) is an enzyme that plays a crucial regulatory function in almost all cells. It facilitates the conversion of ATP to $3^{\prime} 5^{\prime}$ - cyclic AMP (cAMP) and pyrophosphate. The resultant cAMP operates as a regulatory factor by activation of cAMP-binding proteins, transcription factors, or other enzymes (e.g. cAMP-dependent kinases). MDH acts in the Krebs cycle. It catalyses: the conversion of malate to oxaloacetate and also replenishing level of oxaloacetate via pyruvate reductive carboxylation.

An embryonic DC-8-like protein-8803 also showed significant overexpression (Table 2; Fig. 1A); generally, its content decreases during the initial phase of maize seeds imbibition (Tnani et al. 2012), and this phase, in a case of hydroconditioned seeds, took place just during priming hydration.

It should also be noted that three of the stress-related proteins that occurred in embryos of all seed variants showed overexpression in the control ones: general stress protein 39-5502; heat shock 70-kDa mitochondrial-like protein-2901; glyoxalase family protein-1001; moreover, another protein of unknown function-secreted protein-5402 also showed significant overexpression (Table 2; Fig. 1A). However, the above-described metabolism improvement in nt seed axes is not so significant compared with the effects of the aforementioned completely new stress proteins in primed seed axes (Table 1; Fig. 1BCD) as well as to a significant overexpression in the primed seed embryos of four other proteins that were present in all seed variants: protein $\mathrm{Z}-4601 ; 16.9-\mathrm{kDa}$ class I heat shock protein 1-5001; stress-inducible membrane pore protein-7002; and other (different pI values in comparison with spot 5502) general stress protein 39-3301 (Table 2; Fig. 1).

Moreover, the enzymes most important for the energy metabolism, i.e.: triose-phosphate isomerase-4201; cytosolic 3-phosphoglycerate kinase-4701; fructose-bisphosphate aldolase-8601; fructose-bisphosphate aldolase cytoplasmic isozyme-8604; succinyl-CoA ligase alphachain $2-8602$, occurred in much greater quantities in the embryos of conditioned seeds (Table 2, Fig. 1BCD). Triosephosphate isomerase (TPI) plays a significant role in glycolysis and is fundamental for efficacious energy generation. It makes possible interconversion of dihydroxyacetone phosphate and D-glyceraldehyde-3-phosphate. Phosphoglycerate kinase (PGK) enables the phosphate group transfer from 1,3-bisphosphoglycerate into ADP, forming ATP and 3-phosphoglycerate. This is one of the two substrate-phosphorylation reactions during glycolysis. Moreover, fructose-1,6-bisphosphate aldolase catalyses the cleavage of fructose 1,6-bisphosphate to glyceraldehyde 3-phosphate and dihydroxyacetone phosphate (DHAP). The last of mentioned above enzymes-succinyl-CoA ligase [GDP-forming] - participates in the Krebs cycle and propanoate metabolism, and thus, it also affects the improvement of energy metabolism.

In addition, some kinases crucial for signals transduction were also overexpressed in axes of primed seeds, e.g.: nucleoside diphosphate kinase-6003 and nucleoside diphosphate kinase 4-8001; (Table 2, Fig. 1BCD). Nucleoside diphosphate kinases (NPcs) are involved in the nucleoside triphosphates (NTPs) generation, and they act in various regulatory processes related to proliferation, differentiation and development. For example, they are essential for DNA and RNA synthesis-thus crucial for metabolism of macromolecules, cell division, and growth.

As it was mentioned earlier, it is difficult to compare proteomes of Arabidopsis seeds with those of monocotyledonous corn, especially that in research concerning Arabidopsis, whole seeds were usually used, while in the case of corn seeds, we were able to isolate from them the parts which were most active during germination, i.e. embryonic axes. The one important effects of hydropriming common for both plants considered in overexpression of glyceraldehyde-3-phosphate-dehydrogenase in Arabidopsis and appearance of its additional isoforms in corn axes (Table 1; Gallardo et al. 2001). In Arabidopsis, this enzyme was correlated with the secondary desiccation 
(drying after seed priming hydration/imbibition) (Gallardo et al. 2001). Moreover, it was also reported to be a molecular seed vigour marker in Beta vulgaris seeds (Catusse et al. 2011).

In our hydroprimed plant material WD-40 proteins, aconitase and such a great amount of seed storage proteins subunits (12S) as in Arabidopsis (Gallardo et al. 2001) were not observed. The latter ones might not be detected because of storage tissues absence in our material (only axes). However, as concerns storage proteins, we observed that cupin translocation to the axes was much more efficient in the primed corn (especially when priming was supplemented with melatonin) than in the control.

Moreover, overexpression of tubulin and catalase (CAT) observed in Arabidopsis was not noted in our material. Out of energetic metabolism enzymes, other than phosphoenolopyruvate carboxykinase were overexpressed in corn. On the other hand, increase in HSP proteins was observed both in Arabidopsis and corn; however, in corn, not only $18 \mathrm{kDa}$ but also 22- and 70-kDa HSPs were detected. (Tables 1, 2; Gallardo et al. 2001). In general, the spectrum of anti-stress and defence proteins induced by priming was wider in corn than in Arabidopsis.

It is difficult to find precise similarities between seed plant standard (Arabidopsis) and our plant material in terms of their reactions to hydropriming, but it is certainly possible to compare changes in the proteins of specific functional groups, such as: protein mobilising reserves (different enzymes depending on the seed storage material), those responsible for energy processes in cells (glycolytic enzymes, and involved in the Krebs cycle) as well as anti-stress and defence ones (e.g. various HSP, LEA, TRX, and ANP).

To sum up, significant improvement of metabolic processes involved in energy production as well as biosynthesis of anti-stress/stress-induced protective proteins before the occurrence of stress conditions are the facts that explain positive effects of hydroconditioning on seed quality.

\section{Influence of melatonin on axes proteome in germinated maize grains}

Presented results are the first that describe influences of exogenous melatonin on embryo's proteome during early stages of seed germination. Only one paper concerning proteomic modifications during leaf senescence in Malus hupehensis treated with exogenous melatonin has been published so far (Wang et al. 2014). Thus, those researches have been performed with completely different plant materials and focused on different developmental stages and processes (senescence).
Application of melatonin during the hydropriming treatment resulted in stronger improvement of energy metabolism in axes-compared with the only hydroprimed seed variant. Especially, the dose of 50- $\mu \mathrm{M}$ melatonin provoked a synthesis of additional six isoforms of enzymes involved in the sugar metabolism through glycolysis and gluconeogenesis processes (i.e. fructokinase $1-1501$; 2,3-bisphosphoglycerate-independent phosphoglycerate mutase isoform $\mathrm{X} 1-4805$; triosephosphate isomerase, cytosolic-3805; aldolase 1 = fructose-bisphosphate aldolase cytoplasmic isozyme-7701; glyceraldehyde-3-phosphate dehydrogenase1 isoform 1-7603 and glyceraldehyde-3-phosphate dehydrogenase 1 cytosolic isoform X1-7702) and also two of the crucial enzymes in the citric acid cycle (succinyl-CoA ligase beta-chain - 2602 and malate dehydrogenase-5504) (Table 1; Fig. 1C).

A very interesting result, according to Szafranska et al. (2012) research, is the fact confirming that melatonin applied to seeds stimulates polyphenol metabolism. Only in the embryos, proteome of melatonin treated seeds synthesis of 2-dehydro-3-deoxyphosphooctonate aldolase (8506) was observed (Table 1; Fig. 1CD). This enzyme is involved in the shikimate pathway. Members of its family catalyse first steps during biosynthesis of aromatic amino acids. Secondary metabolites accumulation often occurs in plants subjected to different stresses, various elicitors, and also by direct signal molecules action. It is widely known that secondary metabolites are essential for plant interaction with its environment, for adaptation and defence against stress conditions (Bennett and Wallsgrove 1994; Janas et al. 2009b; Ramakrishna and Ravishankar 2011).

In the case of embryos from seeds pretreated with melatonin, a significant improvement of the processes related to the biosynthesis, modifications, and protein destination and storage was observed. In axes of both seed variants treated with melatonin, additional transcription factor 60S acidic ribosomal eukaryotic protein P0 (2503), which composed large subunit of ribosome (it forms main structure in the large subunit, and it is believed to be linked with GTPase activities during protein biosynthesis), as well as directly involved in translations elongation factor 1-delta 1 (EF1B'-0301), occurred. Additionally, elongation factor 1-beta (EF1B-0303) was characteristic for axes from HMel50 seeds (Table 1, Fig. 1CD). Both EF1B' and EF1B catalyse the exchange of GDP bound to the G-protein, for GTP, and this is vital step in elongation processes during protein formation. EF1A - the overexpression of which was observed in all variants of conditioned seed axes (Table 2)-is related to deliver the aminoacyl-tRNA to the ribosome. Eukaryotes eEF1-alpha interacts with the cytoskeleton by actin and may thereby play important role in cellular transformation or apoptosis. This with the simultaneous occurrence of proliferating-associated protein 
2G4 (7804), actin-depolymerizing factor 3 (2001), GTPase-activating protein AGD11 (8101) and of DNA repair protein RAD 23 (0701) in HMel50 seeds (Table 1; Fig. 1C) resulted in intense proliferation and better cell growth of the embryos pretreated with melatonin.

As mentioned earlier, already seed hydroconditioning treatment stimulated the biosynthesis of stress proteins in embryos ( 5 additional spots in B, C, D gels), while melatonin added at the same time provoked additional 3 protein spots in both melatonin seed variants (small HSP-3105, 7102 and thioredoxin TRp26 isoform 4-0203) (Table 1, Fig. 1CD) and 7 anti-stress proteins in HMel50 seeds (co-chaperone protein SBA1-0201; translationally controlled tumour protein (TCTP) homolog-0202; universal stress family protein (USP)_0501; hypothetical protein ZEAMMB73_6828762601; 1-Cys peroxiredoxin antioxidant PER1-6201; glyoxalase I-2402; and esterase D_6402) (Table 1; Fig. 1C).

SBA1 is an alpha-crystallin-HSPs p23-like protein. TCTP is a highly conserved protein associated with a variety of cellular processes. Primarily, it acts as a molecule that prevents cell death via calcium binding and microtubule stabilization. TCTP also reduces cellular stress acting as molecular chaperone like HSP.

USP family is composed of small cytoplasmic proteins highly expressed as response to various stress factors. USP improves cell survival during prolonged exposure to harmful conditions, and may provide an overall "stress endurance". Hypothetical protein ZEAMMB73_682876 showed $88 \%$ identities to protein DJ-1 B-like homolog [Setaria italica]. This DJ-1 homolog exhibits chaperonelike properties, and it is activated together with genes related to oxidative stress response in plants.

In addition, peroxiredoxins (PRXs) are involved in redox status regulation in cells. Subfamily of 1-Cys-PRX is composed of PRXs containing only one conserved cysteine. This amino acid operates as peroxidatic agent. Thus, PRXs are homodimeric thiol-specific antioxidants, which play defensive role by reduction of organic hydroperoxides, peroxynitrite, and excess of hydrogen peroxide in plant cells. While glyoxalases and esterases are typical detoxifying enzymes; glyoxalase I (other name: lactoylglutathione lyase) catalyses the hemithioacetal isomerization, formed by a glutathione and 2-oxoaldehyde, to S-Dlactoyl-glutathione. It is considered as a part of two-step system (called glyoxalase system) for detoxication of methylglyoxal (toxic side product of glycolysis).

Esterases and lipases interact with carboxylic esters. Many of them participate in the first phase of xenobiotics metabolism (especially toxins). The resulting this way carboxylates is then joined by other enzymes to increase their solubility and/or eventually for their excretion.
Quantitative analyses revealed that although the two glycolytic enzymes were overexpressed in axes of hydroprimed seeds $(\mathrm{H})$ (cytosolic glycerqaldehyde-3-phosphate dehydrogenase-8501 and fructose-bisphosphate aldolase, cytoplasmic isozyme-8604) (Table 3; Fig. 1), their other isomeric forms were present in much greater quantity in axes of seeds conditioned with melatonin (glyceraldehyde3-phosphate dehydrogenase 2, cytosolic-5602 and fructose-bisphosphate aldolase-8601) (Table 3; Fig. 1). In general, comparing the enzymes involved in energy metabolism a significant number (6) was overexpressed in the seeds hydroconditioned with melatonin compared with those hydroprimed without it. They were 6-phosphogluconolactonase isoform 2-2301, enolase-2701, triosephosphate isomerase, cytosolic-4202, malate dehydrogenase-4602, cytosolic 3-phosphoglycerate kinase4701 and succinyl-CoA ligase alpha-chain 2-8602 (Table 3; Fig. 1).

Many proteins involved in protein destination, storage and turnover also were overexpressed under the influence of melatonin compared all hydroprimed seeds (i.e. chaperonin 60-2802, mitochondrial chaperonin-60-2903, globulin 2-3101, globulin-1 S allele precursors-3101 and 4003, proteasome subunit alpha type-5304, and unnamed protein product similar to proteasome subunit beta type 6 precursor-4203) (Table 3; Fig. 1CD). In the axes of hydroconditioned seeds in this functional protein group, only one cupin (8103) was overexpressed.

As concerns stress-related and defence proteins, 4 of them (i.e. HSP 26-1202, 1-Cys peroxiredoxin antioxidant-5202, general stress protein 39-5502, thioredoxin h2 protein-6001) were overexpressed in the hydroprimed seed axes (Table 3; Fig. 1B) and 8 in the axes from seeds hydroprimed with melatonin (i.e. glyoxalase family protein superfamily - 1001, glyoxalase family protein isoform 2 3401 , other general stress protein 39-4502, protein $\mathrm{Z}$ 4601, 22.0 kDa class IV HSP precursor-5102, glutathione transferase III(a) — 5201, formate dehydrogenase 1-6702, and hypothetical protein ZEAMMB73_578099 similar to stress responsive protein-7501) (Table 3; Fig. 1CD).

Again, it was confirmed that melatonin applied to the seed affects polyphenols metabolism. In axes of HMel50 seeds, significant overexpression of caffeoyl-CoA $O$ methyltransferase 1 (1303) was observed in comparison with $\mathrm{H}$ seeds (Table 3; Fig. 1BC). It is an enzyme that catalyses the reaction between $S$-adenosyl-L-methionine and caffeoyl-CoA, which are transformed to $S$-adenosyl-Lhomocysteine and feruloyl-CoA. A large number of secondary metabolites are generated via a step involving this enzyme. In general, it participates in phenylpropanoid biosynthesis. 


\section{Conclusions}

To sum up (Fig. 2), hydropriming (H, HMel50, HMel500) provoked biosynthesis of 14 new, characteristic proteins in embryonic axes of the grains germinated at optimal temperature compared with the non-treated ones. When this pre-sowing treatment was supplemented with melatonin (HMel50, HMel500), additional 14 proteins occurred. Moreover, in the seed variant HMel50 (optimal melatonin concentration) -23 and in HMel500-3 characteristic spots were noticed. The majority of additional proteins belonged to energy metabolism enzymes, proteins involved in proteome plasticity via improving protein synthesis, folding, destination and storage, and-most importantlydefence, anti-stresses and detoxifying proteins.

Proteins belonging to these functional groups are frequently ranked as seed quality markers. Particularly, important are those considered to be anti-stress proteins, e.g. HSP, LEA, TRX, and other general stress proteins (Gallardo et al. 2001; Catusse et al. 2011; Wu et al. 2011). Especially, many of these proteins were determined in the corn seeds conditioned with melatonin.

In the literature, the beneficial effect of antioxidant enzymes, i.a. superoxide dismutase (SOD), CAT, glutathione-S-transferase (GST) on seed quality improvement, was underlined (Gallardo et al. 2001; Catusse et al. 2011). However, in our study, we did not observe any differences in the synthesis of these enzymes in the compared seed variants. It seems possible that supplementation of the seeds with melatonin — a highly effective, small molecule antioxidant - and overexpression of other antioxidant and detoxifying factors, such as TRXs, glioxylases, and improved polyphenol biosynthesis, were enough to regulate internal redox balance, and additional antioxidant enzymes were not needed in the conditioned (improved) seeds.

Moreover, the following factors are important for better seed vigour and quality, on the one hand, efficacious reserve mobilisation, and thus increase in the seed storage proteins, such as cupins and/or globulins- their translocation into embryonic axes of the conditioned corn seeds was noted in the presented study - and, on the other hand, the highly productive energy metabolism. With regard to that overexpression of gliceraldehyd-3-phosphate-dechydrogenase observed by us was also mentioned by other authors (Gallardo et al. 2001; Catusse et al. 2011; Wu et al. 2011), however, other glycolytic or Krebs cycle enzymes indicated as vigour markers were different depending on the seed type. In addition, Catusse et al. (2011) also pointed to the voltage-dependent anion channels (VDACs) as these markers, which were confirmed neither by other authors nor by us.
It seems that when determining markers of seed quality attention should also be paid to the proteins involved in sulphur assimilation and metabolism. Similarly, with regard to that also various proteins were indicated by scientists, i.a. phosphoserine aminotranspherase, $S$-adenosylL-methionine synthetase, serine hydroxymethyl transpherase (Catusse et al. 2011), but in most reports as well as in our work, cysteine synthase appeared (Gallardo et al. 2001; Catusse et al. 2011; Wu et al. 2011).

Unfortunately, it seems that the determination of specific seed quality markers will be really difficult due to the variety of seed material subjected to tests under different conditions. However, it is possible to indicate functional groups in which overexpression of different proteins could be beneficial for seed vigour improvement.

Indicating such protein groups and also specific examples for the tested plant material (Table 1), we partially explained why the hydroprimed corn seeds-especially hydroprimed with melatonin, and the seedlings grown from them were stronger in comparison with the non-treated ones, and so quickly and efficiently adapted to the changing environmental conditions (Posmyk et al. 2008, 2009a, b; Janas et al. 2009a). They could be a priori prepared to defence against potential harmful condition. In embryonic axes during the initial state of growth, even under optimal conditions, a number of antioxidative, detoxifying, and chaperon proteins were synthesized. Moreover, the supply of energy from seed storage substances was pretty intensified. The presented results for the first time direct explain how melatonin acts in seed axes as plant stress defence factor. It could be taken as a part of explanation why various plant species with higher content of melatonin have shown improved tolerance to stress (Park et al. 2013; Bajwa et al. 2014; Zhang et al. 2015).

Since melatonin is safe for environment (non-toxic, of natural origin, biodegradable) as well as being inexpensive, it is using as a supplement of various priming methods may be a reliable and cost-effective manner for beneficial seed quality modifications and could be economically favourable for organic farming (Janas and Posmyk 2013). Plant biostimulation by melatonin application is a promising tool to enhance ecological crops and to support safety-food production.

Author contributions statement Izabela Kołodziejczyk -all experiments concerning corn seeds, protein extraction, purification and 2D separation, data acquisition and PDQuest analysis/interpretation. Katarzyna Dzitkomethodological consultant and technical support, optimisation of $2 \mathrm{D}$ separation method for corn seed proteins. Rafał Szefczyk-LC-MS/MS and statistical analysis, database searches. Małgorzata M. Posmyk-work con- 
ception, obtaining of funding, data analysis and interpretation, drafting of the manuscript, responsible for the integrity of the work.

Acknowledgments Presented research was supported by the National Science Centre of Poland as NCN NN310 111940 project.

Open Access This article is distributed under the terms of the Creative Commons Attribution 4.0 International License (http://crea tivecommons.org/licenses/by/4.0/), which permits unrestricted use, distribution, and reproduction in any medium, provided you give appropriate credit to the original author(s) and the source, provide a link to the Creative Commons license, and indicate if changes were made.

\section{References}

Arnao MB, Hernández-Ruiz J (2007) Melatonin promotes adventitious and lateral root regeneration in etiolated hypocotyls of Lupinus albus L. J Pineal Res 42:147-152

Bajwa VS, Shukla MR, Sherif SM, Murch SJ, Saxena PK (2014) Role of melatonin in alleviating cold stress in Arabidopsis thaliana. J Pineal Res 56:238-245

Basak A (2008) Biostimulators-definitions, classification and legislation. In: Gawronska H (ed) Biostimulators in modern agriculture. Editorial House Wies Jutra, Warszawa, pp 7-17

Bennett RN, Wallsgrove RM (1994) Secondary metabolites in plant defence mechanisms. New Phytol 127:617-633

Bevan M, Bancroft I, Bent E et al (1998) Analysis of $1.9 \mathrm{Mb}$ of contiguous sequence from chromosome 4 of Arabidopsis thaliana. Nature 391:485-488

Bradford MM (1976) A rapid and sensitive method for the quantitation of microgram quantities of protein utilizing the principle of protein-dry binding. Anal Biochem 72:248-254

Bradford KJ, Bewley JD (2002) Seeds: Biology, technology and role in agriculture. In: Chrispeels MJ, Sadava DE (eds) Plants, genes and crop biotechnology. Jones and Bartlett, Boston, pp 210-239

Catusse J, Meinhard J, Job C, Strub JM, Fischer U, Pestsova E, Westhoff P, Van Dorsselaer A, Job D (2011) Proteomics reveals potential biomarkers of seed vigor in sugarbeetrt. Proteomics 11:1569-1580

Chen K, Arora R (2013) Priming memory invokes seed stresstolerance. Environ Exp Bot 94:33-45

Chen Q, Qi WB, Reiter RJ, Wei W, Wang BM (2009) Exogenously applied melatonin stimulates root growth and raises endogenous indoleacetic acid in roots of etiolated seedlings of Brassica juncea. J Plant Physiol 166:324-328

Di Girolamo G, Barbanti L (2012) Treatment conditions and biochemical processes influencing seed priming effectiveness. Ital J Agron 7:178-188

Dunwell JM, Purvis A, Khuri S (2004) Cupins: the most functionally diverse protein superfamily? Phytochemistry $65: 7-17$

Eskandari H (2013) Effects of priming technique on seed germination properties, emergence and field performance of crops-a review. Int J Agron Plant Prod 4:454-458

Fu Z, Jin X, Ding D, Li Y, Fu Z, Tang J (2011) Proteomic analysis of heterosis during maize seed germination. Proteomics 11:1462-1472

Gallardo K, Job C, Groot SP, Puype M, Demol H, Vandekerckhove J, Job D (2001) Proteomic analysis of Arabidopsis seed germination and priming. Plant Physiol 126:835-848

Gong F, Wu X, Wang W (2013) Comparative proteomic identification of embryo proteins associated with hydropriming induced rapidgermination of maize seeds. Plant Omics 6:333-339
Grover A, Kapoor A, Lakshmi OS, Agarwal S, Sahi C, KatiyarAgarwal S, Agarwal M, Dubey H (2001) Understanding molecular alphabets of the plant abiotic stress responses. Curr Sci 80:206-216

Hernández-Ruiz J, Arnao MB (2008) Melatonin stimulates the expansion of etiolated lupin cotyledons. Plant Growth Regul 55:29-34

Hernández-Ruiz J, Cano A, Arnao MB (2005) Melatonin acts as a growth-stimulating compound in some monocot species. J Pineal Res 39:137-142

Janas KM, Posmyk MM (2013) Melatonin, an underestimated natural substance with great potential for agricultural application. Acta Physiologiae Plantarum 35:3285-3292

Janas KM, Ciupińska E, Posmyk MM (2009a) Melatonin applied by hydropriming, as phytobiostimulator improving corn (Zea mays L.) seedlings growth at abiotic stresses conditions. In: Li S, Wang $\mathrm{Y}$, Cao $\mathrm{F}$, Huang $\mathrm{P}$, Zhang $\mathrm{Y}$ (eds) Progress in environmental science and technology, vol II A. Science Press USA Inc., pp 383-388, ISBN 978-7-03-024459-8

Janas KM, Amarowicz R, Zielińska-Tomaszewska J, Kosinska A, Posmyk MM (2009b) Induction of phenolic compounds in two lentil cultivars with different tolerances to copper ions. Acta Physiol Plant 31:587-595

Jisha KC, Vijayakumari K, Puthur JT (2013) Seed priming for abiotic stress tolerance: an overview. Acta Physiol Plant 35:1381-1396

Kołodziejczyk I, Dzitko K, Szewczyk R, Posmyk MM (2016) Exogenous melatonin improves corn (Zea mays L.) embryo proteome in seeds subjected to chilling stress. J Plant Physiol 193:47-56

Mabhaudhi T, Modi AT (2011) Can hydropriming improve germination speed, vigour and emergence of maize landraces under water stress? J Agric Sci Technol B 1:20-28

Park S, Lee DE, Jang H, Byeon Y, Kim YS, Back K (2013) Melatonin rich transgenic rice plants exhibit resistance to herbicide-induced oxidative stress. J Pineal Res 54:258-263

Posmyk MM, Kuran H, Marciniak K, Janas KM (2008) Pre-sowing seed treatment with melatonin protects red cabbage seedlings against toxic copper ion concentrations. J Pineal Res 45:24-31

Posmyk MM, Bałabusta M, Janas KM (2009a) Melatonin applied by osmopriming, as phytobiostimulator improving cucumber $\mathrm{C} \mathrm{Cu}$ cumis sativus $\mathrm{L}$.) seedlings growth at abiotic stresses conditions. In: Li S, Wang Y, Cao F, Huang P, Zhang Y (eds) Progress in environmental science and technology, vol II A. Science Press USA Inc., pp 362-369, ISBN 978-7-03-024459-8

Posmyk MM, Bałabusta M, Wieczorek M, Sliwinska E, Janas KM (2009b) Melatonin applied to cucumber (Cucumis sativus L.) seeds improves germination during chilling stress. J Pineal Res $46: 214-223$

Rahimi A (2013) Seed priming improves the germination performance of cumin (Cuminum syminum L.) under temperature and water stress. Ind Crops Prod 42:454-460

Ramakrishna A, Ravishankar GA (2011) Influence of abiotic stress signals on secondary metabolites in plants. Plant Signal Behav 6:1720-1731

Sarrou E, Therios I, Dimassi-Theriou K (2014) Melatonin and other factors that promote rooting and sprouting of shoot cuttings in Punica granatum cv. Wonderful. Turk J Bot 38:293-301

Szafrańska K, Glińska S, Janas KM (2012) Changes in the nature of phenolic deposits after re-warming as a result of melatonin presowing treatment of Vigna radiata seeds. J Plant Physiol 169:34-40

Timperio AM, Egidi MG, Zolla L (2008) Proteomics applied on plant abiotic stresses: role of heat shock proteins (HSP). J Proteomics 71:391-411

Tnani H, López I, Jouenne T, Vicient CM (2012) Quantitative subproteomic analysis of germinating related changes in the scutellum oil bodies of Zea mays. Plant Sci 191:1-7 
Vieira Dos Santos C, Rey P (2006) Plant thioredoxins are key actors in the oxidative stress response. Trends Plant Sci 11:329-334

Wang WX, Vinocur B, Shoseyov O, Altman A (2004) Role of plant heat-shock proteins and molecular chaperones in the abiotic stress response. Trends Plant Sci 9:1360-1385

Wang P, Sun X, Xie Y, Li M, Chen W, Zhang S, Liang D, Ma F (2014) Melatonin regulates proteomic changes during leaf senescence in Malus hupehensis. J Pineal Res 57:291-307

Wu X, Liu H, Wang W, Chen S, Hu X, Li C (2011) Proteomic analysis of seed viability in maize. Acta Physiol Plant 33:181-191

Zhang N, Zhao B, Zhang H-J, Weeda S, Yang Ch, Yang Z-C, Ren S, Guo Y-D (2013) Melatonin promotes water-stress tolerance, lateral root formation, and seed germination in cucumber (Cucumis sativus L.). J Pineal Res 54:15-23

Zhang N, Zhang HJ, Zhao B, Sun QQ, Cao YY, Li R, Wu XX, Weeda S, Li L, Ren S, Reiter RJ, Guo YD (2014) The RNA-seq approach to discriminate gene expression profiles in response to melatonin on cucumber lateral root formation. J Pineal Res 56:39-50

Zhang N, Sun Q, Zhang H, Cao Y, Weeda S, Ren S, Guo YD (2015) Roles of melatonin in abiotic stress resistance in plants. J Exp Bot 66:647-656 